\title{
Cédulas de profesión del monasterio de Valbuena de Duero en el Archivo Histórico Nacional*
}

Profession letters at the monastery of Valbuena de Duero in the Archivo Histórico Nacional

\section{Guillermo FERNÁNDEZ ORTIZ}

Universidad de Oviedo (Área de Ciencias y Técnicas Historiográficas)

https://orcid.org/0000-0002-4572-8236

fernandezguillermo@uniovi.es

Abstract: We study and catalogue the profession charts belonging to the monastery of Valbuena de Duero, which are deposited today in dossier 7658 of the Clergy Section of the National Historical Archive of Spain. We approach the analysis of these from the perspective of Diplomatic Science.

Keywords: Valbuena de Duero; Early Modern Diplomacy; Cistercian Congregation of Castile; Paper Watermark.
Resumen: Se ofrece el estudio y catálogo de cédulas de profesión que, procedentes del archivo del desamortizado monasterio de Valbuena de Duero, se conservan actualmente en el legajo 7658 de la sección clero regular del Archivo Histórico Nacional. Se ha realizado una aproximación a su análisis desde la perspectiva de la diplomática.

Palabras clave: Valbuena de Duero; Diplomática moderna; Congregación cisterciense de Castilla; Filigranas del papel.

El monasterio de Valbuena de Duero (Valladolid) fue fundado por la condesa Estefanía Armengol, quien en el año 1143 le hizo dotación de las villas de Valbuena y Murviedro, tal y como se contiene en un privilegio «confirmado y realizado bajo la supervisión» de Alfonso VII ${ }^{1}$. La primera comunidad de religiosos estuvo sometida a la regla de San Benito y, según estimación de Álvarez Palenzuela, solo a inicios de la década de 1150, con la instalación de monjes de origen francés, abrazó los usos cistercienses².

* Abreviaturas utilizadas: ARCHIVO HISTÓRICO NACIONAL [= AHN].

1 Vicente Álvarez Palenzuela y Manuel Recuero ASTRAY, La fundación de monasterios cistercienses en Castilla: cuestiones cronológicas e ideológicas, en Hispania Sacra, 74 (1984), p. 436.

2 Vicente Álvarez PalenZuela y Manuel ReCUERo ASTRAY, La fundación de monasterios cistercienses..., [ver n. 1], pp. 444, 445 y 447; Javier PÉREZ-EMBID WAMBA, El Císter en Castilla y León. Monacato y dominios rurales (ss. XII-XV), Salamanca, 1986, pp. 271 y 275; Antonio GARCÍA FLORES, Arquitectura de la Orden del Císter en la Provincia de Valladolid (1147-1515), Valladolid, 2010, pp. 189-194. 
En los primeros años de la institución parece que el emperador se constituyó en su principal impulsor, haciéndole concesión de coto en el año 1153 y otorgando otros instrumentos en su favor ${ }^{3}$. Tras él, sus sucesores en el trono debieron de continuar en la misma línea, y así dispusieron para la comunidad de Valbuena varios privilegios de concesión (pozo de sal en Bonilla, derechos sobre los montes de Peñafiel) y de exención (del pago de portazgos, por parte de Fernando III, por ejemplo $)^{4}$. La nobleza local también contribuyó al enriquecimiento del dominio territorial de los bernardos de Valbuena, pero la escasez del fondo documental, impide hacer grandes precisiones ${ }^{5}$.

Los monjes, por su parte, no dejaron de ampliar, redondear y articular su patrimonio fundiario. Así, como expone García Flores, desde el siglo XIV tendieron a desprenderse de las propiedades más alejadas y a adquirir bienes en términos más próximos a la abadía ${ }^{6}$. Será en enclaves en los que ya se concentraban sus mayores intereses, como en Piñel o Valbuena, donde la compra de viñas esté bien atestiguada en el último tercio del cuatrocientos ${ }^{7}$. Para la puesta en explotación de estos bienes y de los ingenios agrícolas que llegaron a acumular se sirvieron del censo enfiteútico y de otros vínculos contractuales (arrendamientos, foros...) de amplia difusión en la Baja Edad Media ${ }^{8}$. La cabaña ganadera, de suidos y ovicápridos, también reportó ingresos destacados a las arcas monásticas?

En el siglo XIV el monasterio entró, como la mayoría de sus homólogos, en una situación de crisis y relajación. Los pleitos se sucedieron con los concejos vecinos (Peñafiel, Castroverde, Piñel de Arriba y Piñel de Abajo, entre otros) ${ }^{10}$,

3 Vicente Álvarez Palenzuela y Manuel Recuero Astray, La fundación de monasterios cistercienses... [ver n. 1], pp. 437-445.

4 Antonio García Flores, Arquitectura de la Orden del Císter... [ver n. 2], p. 195. Sobre la exención de portazgo vid. también Javier PÉREZ-EMBID WAMBA, El Císter en Castilla y León... [ver n. 2], p. 317.

5 Antonio García Flores, Arquitectura de la Orden del Císter... [ver n. 2], pp. 194-195.

6 Ibid. [ver n. 2], p. 197.

7 Lorenzo MATÉ SADORNIL, Cuentas del monasterio de Valbuena (s. XV), en VV.AA., VI Encuentro de trabajo sobre Historia de la Contabilidad, [sin lugar], 2009, p. 9.

8 Ms. MADRID, AHN. Sección Clero. Regular. Cistercienses. Valbuena de Duero. 7666. Censo del molino de Villaboz (1443).

9 Lorenzo MATÉ SADORNIL, Cuentas del monasterio... [ver n. 7], pp. 11-13.

10 Antonio García Flores, Arquitectura de la Orden del Císter... [ver n. 2], p. 197. Pleitos con los concejos ya se venían registrando desde la centuria anterior, Javier PÉREZ-EMBID WAMBA, Violencias y luchas campesinas en el marco de los dominios cistercienses castellanos y leoneses de la Edad Media, en VV.AA., El Pasado Histórico de Castilla y León. Volumen I: Edad Media, Burgos, 1983, p. 162. Noticias sobre algunos de los enfrentamientos entre Peñafiel, Piñel y el monasterio a lo largo de los siglos XV y aún XVI en Ms. MADRID, AHN. Sección Clero. Regular. Cistercienses. Valbuena de Duero. 7658. Advertencias acerca del pleyto que el monasterio de Valbuena trata con Peñafiel y Piñel sobre 
en una espiral de conflictividad que no desaparecerá en la Edad Moderna ${ }^{11}$. En cambio, la incorporación del monasterio a la Reforma cisterciense encabezada por fray Martín de Vargas sí supondrá un cambio de tendencia para la historia de la institución ${ }^{12}$. En el discurrir de los siglos XV y XVI Valbuena adquirirá una importancia no conocida hasta entonces y muchos monjes formados en su claustro ocuparán los puestos de responsabilidad en el seno de la Congregación cisterciense de Castilla, participando además de la introducción de los nuevos usos en las abadías del Noroeste ${ }^{13}$; se renovará la fábrica del propio conjunto monástico, adaptándolo a las exigencias de la reforma ${ }^{14}$; y se adoptarán las prácticas administrativas que irá regulando el órgano central de la Observancia cisterciense castellana, sustentadas en buena medida en el continuo concurso de lo escrito ${ }^{15}$.

\section{OBJETIVOS Y FUENTES}

En las páginas que siguen se ofrece el catálogo de cédulas de profesión que procedentes del archivo del desaparecido monasterio de Valbuena de Duero se conservan actualmente en el legajo 7658 de la sección clero regular del Archivo Históri-

los montes altos; también, Ms. MADRID, AHN. Sección Clero. Regular. Cistercienses. Valbuena de Duero. 7666. Carpetilla: Sentencia arbitraria del licenciado Illescas y del bachiller Pedro Pérez entre el monasterio y Peñafiel (1477).

11 Entre muchos otros testimonios, pueden citarse, a propósito de los numerosos conflictos documentados en la Edad Moderna, Ms. MADRID, AHN. Sección Clero. Regular. Cistercienses. Valbuena de Duero. 7658 [Parecer sobre el pleito que litiga el monasterio de Valbuena con las villas de Peñafiel y Cuéllar (1702); Pleito por los diezmos de las villas de Quintanilla de Arriba, Valbuena... con los párrocos (1675)]. Ms. MADRID, AHN. Sección Clero. Regular. Cistercienses. Valbuena de Duero. 7660 [Papeles para el pleito sobre el diezmo de la granja de Tordelaguna (1681)]. Ms. MADRID, AHN. Sección Clero. Regular. Cistercienses. Valbuena de Duero. 7661 [Causa del oficio contra Manuel Alonso, vecino de Peñafiel, por pescar en el río (1680)].

12 Sobre el proceso de incorporación de Valbuena a la Reforma, pueden verse las notas que compendia Antonio GARCía Flores, Arquitectura de la Orden del Císter... [ver n. 2], pp. 198-200.

13 Ms. MADRID, AHN. Sección Clero. Regular. Cistercienses. Valbuena de Duero. 7658. Tabla de los reverendísimos padres generales que han salido de este Real monasterio de Nuestra Señora Santa María de Valbuena de Duero, en la Congregación de los reynos de la Corona de Castilla, del orden de Nuestro padre San Bernardo, que tubo principio el año de 1427.

14 Se ofrecen abundantes informaciones en Antonio García Flores, Arquitectura de la Orden del Císter... [ver n. 2], pp. 201-296. Para obras acometidas en el primer tercio del siglo XVIII puede verse Antonio GARCÍA FLORES, Monje, contrabandista, abad y promotor de las artes: el patrocinio de fray Alonso de la Puente (+ 1729) en el monasterio de Valbuena (Valladolid), en Boletín de la Real Academia de Bellas Artes de la Purísima Concepción, 44 (2009), pp. 61-74.

15 Miguel Calleja Puerta, Libros para la administración. Estado de la cuestión y perspectivas de la investigación, en José Antonio MUNITA LOINAZ y José Ángel LEMA PUEYO (coords.), La escritura de la memoria. Libros para la administración, Bilbao, 2012, p. 35. 
co Nacional ${ }^{16}$. A él llegaron, junto con el resto de documentación de Valbuena, procedentes del Archivo Provincial de Hacienda de Valladolid ${ }^{17}$, pues no pocas cédulas de las conservadas en el archivo madrileño llevan el sello de aquella institución ${ }^{18}$.

De los 89 ejemplares que se recogen en el catálogo, 2 se fechan en el siglo XVI, 23 en el XVII, 47 en el XVIII y 17 en el primer tercio del XIX. Su distribución en el tiempo, como es lógico suponer, tampoco es homogénea.

Tabla 1. Distribución cronológica de las cédulas de profesión

\begin{tabular}{|cccccccccc|}
\hline 1594 & 1599 & 1603 & 1604 & 1606 & 1611 & 1613 & 1616 & 1623 & 1627 \\
\hline 1 & 1 & 1 & 1 & 1 & 1 & 1 & 1 & 1 & 1 \\
\hline 1638 & 1640 & 1647 & 1653 & 1655 & 1660 & 1672 & 1673 & 1687 & 1690 \\
\hline 1 & 1 & 1 & 1 & 1 & 1 & 1 & 1 & 1 & 1 \\
\hline 1694 & 1696 & 1697 & 1699 & 1700 & 1706 & 1725 & 1726 & 1730 & 1731 \\
\hline 1 & 2 & 1 & 1 & 1 & 1 & 2 & 1 & 1 & 1 \\
\hline 1739 & 1749 & 1750 & 1751 & 1753 & 1754 & 1755 & 1757 & 1758 & 1760 \\
\hline 1 & 2 & 1 & 3 & 1 & 1 & 1 & 1 & 1 & 2 \\
\hline 1762 & 1764 & 1766 & 1768 & 1769 & 1771 & 1772 & 1773 & 1775 & 1778 \\
\hline 1 & 2 & 1 & 1 & 1 & 1 & 2 & 1 & 1 & 2 \\
\hline 1779 & 1782 & 1783 & 1785 & 1787 & 1789 & 1791 & 1793 & 1795 & 1798 \\
\hline 1 & 1 & 1 & 3 & 1 & 1 & 1 & 2 & 1 & 1 \\
\hline 1803 & 1804 & 1806 & 1807 & 1826 & 1827 & 1828 & 1830 & 1833 & \\
\hline 1 & 1 & 2 & 4 & 2 & 1 & 1 & 2 & 3 & \\
\hline
\end{tabular}

Fuente: Ms. MADRID, AHN. Sección Clero. Regular. Cistercienses. Valbuena de Duero. Legajo 7658 (1) y 7658 (2).

16 Ms. MAdRID, AHN. Sección Clero. Regular. Cistercienses. Valbuena de Duero. 7658 (1) y (2). Como es bien sabido, aún restan por inventariar los legajos de la serie de papeles de la provincia de Valladolid, entre otras. Vid. Luis Miguel de la CrUZ Herranz, La sección de Clero del Archivo Histórico Nacional, en Juan Carlos GALENDE (coord.), II fornadas científicas sobre documentación de la Corona de Castilla (siglos XIII-XV), Madrid, 2003, p. 428 (n. 171). Hasta la fecha apenas disponemos de la relación de las cédulas de profesión de algunos monasterios: ya en catálogos que incluyen la descripción minuciosa de un fondo, como sucede con el de San Miguel de Dueñas (Gregoria CaVERo DomíngueZ, Catálogo del monasterio de San Miguel de Dueñas, León, 1994); ya en instrumentos o estudios dedicados exclusivamente a este tipo documental: Alicia MARCHANT RIVERA, Las religiosas del císter malagueño. Catálogo de las cartas de profesión de la abadía de Santa Ana, Málaga, 2010; o Ana María CANSECo OYARBIDE, El monasterio cisterciense de Santa María la Real de Arévalo: cédulas de profesión, Oviedo (Tesis de Licenciatura inédita), 1994.

17 Sobre la antigüedad de la documentación eclesiástica y su incautación durante la Desamortización vid. Ángel Laso Ballesteros, Eppur si muove: El Archivo Histórico Provincial de Valladolid, en Soledad CARNICER ARRIBAS y Alberto MARCOS MARTÍN (coords.), Valladolid, ciudad de archivos, Valladolid, 2011, p. 237.

18 Por ejemplo, Catálogo n. ${ }^{\circ}$ 10. El mismo proceso ha sido descrito para la documentación de Nuestra Señora de la Anunciación del Bueso, Ernesto Zaragoza Pascual, Abadologio del monasterio de Nuestra Señora de la Anunciación del Bueso (1460-1789), en Investigaciones Históricas, 21 (2001), p. 25. 
La más antigua data de 11 de abril de $1594^{19}$, mientras que las más recientes llevan fecha de 21 abril de $1833^{20}$. No obstante, tanto antes como después se concedieron hábitos: aún el 8 de febrero de 1835 nos consta haber tenido lugar la profesión de fray Atanasio Salgado ${ }^{21}$. Entre ambas fechas, el número de cédulas que deberían de existir hubo de ser sensiblemente superior ${ }^{22}$.

Actualmente se conservan plegadas sobre sí, procedimiento empleado ya en época histórica. Su estado de conservación es, en términos generales, bueno. No obstante, algunos ejemplares presentan roturas en pliegues ${ }^{23}$ y bordes $^{24}$, y manchas de humedad ${ }^{25}$; mientras, las tintas ferrogálicas han consumido parte del papel de la cédula n. ${ }^{\circ}$. En muy raras ocasiones los desperfectos del soporte han afectado al texto e impiden su íntegra lectura ${ }^{26}$.

\section{NOTAS DE DIPLOMÁTICA}

Desde una perspectiva diplomática nada individualiza la estructura de los ejemplares de Valbuena de los producidos en el resto de abadías masculinas de la Congregación ${ }^{27}$.

En primer lugar figura el pasaje que el hermano postulante había de leer en su ceremonia de profesión, redactado en estilo subjetivo. El texto de las cartas se

19 Catálogo cédula n. ${ }^{\circ} 1$.

20 Catálogo cédulas núms. 87, 88 y 89.

21 Ms. MADRID, AHN. Sección Clero. Regular. Cistercienses. Valbuena de Duero. 7666 [Libro de actas del monasterio. 1803-1835, fol. 79v. ${ }^{\circ}$. Nacido como Bernardo Salgado era hijo de Francisco Salgado y de Ángela Cid, natural del pueblo de Abeledo, parroquia de Santiago da Rábeda (Orense). Se leyeron sus informaciones el 1 de febrero de 1834. Ms. MADRID, AHN. Sección Clero. Regular. Cistercienses. Valbuena de Duero. 7666 [Libro de actas del monasterio. 1802-1835, fol. 77v. ${ }^{\circ}$.

22 Solo entre 1802 y 1833 la serie está completa, pues hay una absoluta correspondencia entre los ejemplares conservados y las ceremonias de profesión celebradas en presencia de la comunidad, según refrendo del secretario de la misma en el Libro de Actas. Ms. MADRID, AHN. Sección Clero. Regular. Cistercienses. Valbuena de Duero, leg. 7666 [Libro de actas del monasterio. 1802-1835].

23 Catálogo, núms. 13, 14, 31, 81 y 89.

24 Catálogo, n. ${ }^{\circ} 76$.

25 Catálogo, núms. 12, 28, 29 y 30.

26 Catálogo, núms. 2, 13 y 17.

27 Guillermo FERNÁNDEZ ORTIZ, Escrituras para la profesión masculina en la orden del Císter, ceremonial y tipologías documentales, en Historia. Instituciones. Documentos, 44 (2017), pp. 221-222. Por su parte, en Francia, desde el siglo XVI se exige a los regulares que lleven registros de las tomas de hábito, de acceso al noviciado y de las de profesión. Vid. Oliver PONCET, Inscrire les clercs dans l'État. La monarchie française, les ecclésiastiques et le gouvernement par l'écrit (XVI ${ }^{e}-X V I I I^{e}$ siècle), en Patrick ARABEYRE y Brigitte BASDEVANT-GAUDEMENT (dirs.), Les clercs et les princes. Doctrines et pratiques de l'autorité ecclésiastique à l'époque moderne, Paris, 2013, pp. 82 y ss. 
atiene al modelo recogido en las definiciones de la Congregación ${ }^{28}$ que se completaba con los datos específicos: el nombre del novicio, del abad que presidía la ceremonia y del monasterio en el que esta tenía lugar.

Precedida de la señal de la cruz, abre la cédula la intitulación del otorgante (ego / yo $N$ ). A continuación figura el dispositivo, que comienza por el verbo (promitto / prometo), por el que aquel hace promesa de su estabilidad, de la conversión de sus costumbres y de obediencia al abad, según las constituciones de la Orden (secundum regulam sancti benedicti abbatis). La cédula va dirigida al padre abad, del que no siempre se indica el apellido, que preside la ceremonia, así como a sus sucesores en el cargo en dicho monasterio, a quienes promete las referidas obediencias y estabilidad ( $t i b i$ / a vos), pues el nuevo monje sería para siempre hijo de esta abadía, debiendo obediencia a sus superiores.

En el caso de aquellos que aspiraban a ser monjes de coro, el pasaje estaba escrito en latín; si quien profesaba lo hacía para hermano lego, el castellano solía ser la lengua empleada ${ }^{29}$. Además, normalmente, si esta última era la opción, aparecía explícitamente, aunque excepciones no faltan ${ }^{30}$.

A continuación, figura en todas las cartas la cruz que trazaba el postulante. Acto seguido, aunque entre los monjes parece haber sido muy raro ${ }^{31}$, podía incluirse el verso Suscipe me Domine secundum eloquium tuum \& vivam. \& non confundas me ab expectatione mea $a^{32}$, que el pretendiente cantaba de vuelta al presbiterio ${ }^{33}$.

Finalmente, se incluye la diligencia de la profesión, escrita en castellano por el recién profeso. Comienza por la data tópica (En el monasterio de Santa María la Real de Valbuena, de la Orden de Cistel, del obispado de Palencia) y cronológica, seguida de la intitulación (nombre en religión, parentesco, lugar de vecindad y edad) ${ }^{34}$. En el dispositivo se incluye el reconocimiento de haber profesado (Hice

28 Diffiniciones cistercienses, Valladolid, 1637, ff. 46v. ${ }^{\circ}-47 \mathrm{r}^{\circ}$.

29 Catálogo, núms. 19, 20, 26, 30, ¿62? y 76. La cédula de profesión de fray Santiago del Valle, quien prometió obediencia como «laicus» estaba escrita en latín. Catálogo cédula n. ${ }^{\circ} 51$. También en latín la cédula . $^{\circ} 24$.

30 Catálogo, n. ${ }^{\circ}$ 76. Fray Bernardo Martín, en el siglo Ignacio Martín, natural de Valbuena de Duero, profesó como hermano hortelano. Ms. MADRID, AHN. Sección Clero. Regular. Cistercienses. Valbuena de Duero, leg. 7666. [Libro de actas del monasterio. 1804-1835, ff. 18v. ${ }^{\circ}$ y $22 \mathrm{r}^{\circ}$ ].

31 No así en las abadías femeninas. Ana María CANSECO OYARBIDE, El monasterio cisterciense de... [ver n. 16], p. 44.

32 Únicamente consta en la cédula de fray Lorenzo de la Torre. Cédula n. ${ }^{\circ} 2$.

33 Así aparece consignado en La Regla de San Benito (edición de de García M. Colombás), Madrid, 1979, cap. LVIII.

34 Exactamente como se documenta en las cartas del convento de Alcalá. María del Val GONZÁLEZ DE LA PEÑA, Aspectos gráficos y visuales de las cartas de profesión monásticas, en Signo, 4 (1997), p. 68. 
profesión), firmándolo él y tres miembros de la comunidad a ruego suyo como refrendo de veracidad.

Cierran el documento las rúbricas del nuevo monje y de sus tres compañeros de hábito ${ }^{35}$. En ocasiones ellos mismos dejan constancia de su rol en el seno de la comunidad ${ }^{36}$ o de la Congregación ${ }^{37}$, en ocasiones es el propio novicio el que lo hace. El abad nunca actúa como firmante.

Con posterioridad, prácticamente todas las escrituras han recibido una nota dorsal en la que se sintetiza su contenido ${ }^{38}$, muy posiblemente en fecha muy próxima a la propia ceremonia. En ellas suele consignarse el hecho documentado, el nombre del religioso, la edad a la que tuvo lugar la profesión y su lugar de vecindad o su «nación»: «Profesión de fray Roberto Martín Tejedor; campesino ${ }^{39}$, su hedad de 17 años, 6 meses y quatro días ${ }^{40} \mathrm{o} \ll+$ Profesión de fray Francisco Criado en 24 de junio de $1807 \gg^{41}$. Tampoco faltan casos en los que una primera descripción fue ampliada en un segundo momento: «+ Professión de el hermano fray Nicolás Álvarez. En 6 de diziembre de 1782 ${ }^{42}$. También hay descripciones más breves.

Todas las cédulas de profesión localizadas son ejemplares en papel, de diferentes dimensiones, calidades y procedencias.

Un aspecto curioso, sin duda alguna, es la orientación del soporte a la hora de ser escrito. Si en un primer momento parece predominar la disposición del texto paralela al lado corto, una vez ya entrado el siglo XVIII, esta forma de proceder va siendo relegada por la tendencia a fijar los renglones paralelos al lado largo, modo que se impone absolutamente desde el último tercio del setecientos, pues desde 1760 no consta caso alguno con el texto dispuesto verticalmente. Por norma general, la cédula se limita al recto del bifolio ${ }^{43}$ y en muy pocas ocasiones se apura la superficie a escriturar.

35 De forma excepcional, cabe citar cómo, en la cédula de profesión de fray Gregorio Galdámez (1754), el padre fray Adriano Palmero no llegó a estampar su firma. Vid. Catálogo cédula n. ${ }^{\circ} 41$.

36 Como priores de Valbuena son presentados fray Juan de Argüello (núms. 3 y 4), fray Martín Alonso (n. ${ }^{\circ}$ 16), fray Agustín de Cervatos (núms. 22 y 23), fray Gaspar Correa (n. $\left.{ }^{\circ} 37\right)$ o fray Clemente Cuevas (núms. 87, 88 y 89); como maestro de novicios fray Juan de Tamayo (n. $\left.{ }^{\circ} 4\right)$, fray Lorenzo Ceballos (n. $\left.{ }^{\circ} 17\right)$ o «mi maestro de novizios» fray Ángel Muñoz (n. $\left.{ }^{\circ} 40\right)$.

37 Con la categoría de padre predicador figura fray Agustín López en 1739 (n. ${ }^{\circ} 33$ ). Como procurador general en la curia romana aparece fray Adriano Palmero en la cédula de fray Hipólito Quirós (n. $\left.{ }^{\circ} 35\right)$; como definidor general fray Eugenio del Corral (n. $\left.{ }^{\circ} 35\right)$.

38 Constituyen una excepción las cédulas de los últimos años (núms. 85-89). La nota archivística de la cédula $n .^{\circ} 5$ también fue escrita en el recto del bifolio.

39 De Tierra de Campos.

40 Cédula n. ${ }^{\circ} 83$.

41 Cédula n. ${ }^{\circ} 79$.

42 Catálogo, n. ${ }^{\circ} 61$. También pueden verse las cédulas núms. 34 y 56.

43 A excepción de la cédula n. ${ }^{\circ} 17$ en la que lo escrito por el postulante continúa en el reverso. 
Además, aún no siendo un procedimiento generalizado, en el siglo XVII, en algunas ocasiones el pliego de papel fue doblado, adoptando la cédula de profesión forma de cuadernillo ${ }^{44}$. En ellos la escritura se fijó paralela al lado corto, ya en el recto del primer folio ${ }^{45}$, ya en el recto del segundo ${ }^{46}$.

Tabla 2. Disposición del texto en el bifolio

\begin{tabular}{|c|c|c|c|c|c|c|}
\hline & $\begin{array}{l}\text { Vertical } \\
\quad \%\end{array}$ & $\begin{array}{c}\text { Horizontal } \\
\%\end{array}$ & $\begin{array}{c}\text { Cuadernillo } \\
\%\end{array}$ & $\begin{array}{c}\text { Vertical } \\
\text { n. }^{\circ}\end{array}$ & $\begin{array}{c}\text { Horizontal } \\
\text { n. }^{\circ}\end{array}$ & $\begin{array}{c}\text { Cuadernillo } \\
\text { n. }^{\circ}\end{array}$ \\
\hline XVI & $100 \%$ & 0 & 0 & 2 & 0 & 0 \\
\hline $\begin{array}{l}\text { 1. }{ }^{a} 1 / 2 \\
\text { s. XVII }\end{array}$ & $72,7 \%$ & $18,2 \%$ & $9,1 \%$ & 8 & 2 & 1 \\
\hline $\begin{array}{l}\text { 2. }{ }^{a} 1 / 2 \\
\text { s. XVII }\end{array}$ & $66,66 \%$ & $8,33 \%$ & $25 \%$ & 8 & 1 & 3 \\
\hline $\begin{array}{l}\text { 1. }{ }^{a} 1 / 2 \\
\text { s. XVIII }\end{array}$ & $40 \%$ & $60 \%$ & 0 & 4 & 6 & 0 \\
\hline $\begin{array}{l}\text { 2. }{ }^{2} 1 / 2 \\
\text { s. XVIII }\end{array}$ & $24,3 \%$ & $75,7 \%$ & 0 & 9 & 28 & 0 \\
\hline s. XIX & 0 & $100 \%$ & 0 & 0 & 17 & 0 \\
\hline
\end{tabular}

Para la escrituración del documento de profesión, los tipos gráficos empleados pertenecen al amplio ciclo de la escritura humanística. Por norma general parece que un monje de la abadía, hábil calígrafo, se encargó de fijar el texto de la promesa que hacía el novicio, no siendo raro encontrar a determinados individuos detrás de la escrituración de varias de ellas ${ }^{47}$, aún sin darse la existencia de auténticos profesionales como se aprecia en los claustros femeninos ${ }^{48}$. Las

44 Cédulas núms. 6, 16, 18 y 19.

45 Cédulas núms. 6 y 19.

46 Cédula n. ${ }^{\circ} 18$.

47 A la mano de fray Eugenio Moreno debemos la promesa de las cédulas núms. 57, 61 y 68. Fray Bernardo Escudero se encargó de la escrituración de los asientos iniciales de las cédulas de fray Ambrosio Pérez (n. $\left.{ }^{\circ} 1\right)$ y fray Lorenzo de la Torre (n. $\left.{ }^{\circ} 2\right)$. Algo similar se observa en el femenino de Santa Ana de Málaga, Alicia MARCHANT RIVERA, Aproximación a la diplomática eclesiástica a través de la documentación conventual: las cartas de profesión de la abadía cisterciense de Santa Ana en Málaga, en Boletín de la Sociedad Española de Ciencias y Técnicas Historiográficas, 3 (2005), p. 327.

48 En Santa Ana de Málaga fueron redactadas por dignidades eclesiásticas en un primer momento, y, en el siglo XX, por personal especializado de la propia comunidad, o ajeno a la misma, Alicia MARCHANT RIVERA, Aproximación a la diplomática eclesiástica... [ver n. 47], pp. 326-327. En Alcalá parece que acudieron a algún especialista, María del Val GONZÁLEZ DE LA PEÑA, Aspectos gráficos... [ver n. 34], p. 75. 
soluciones gráficas adoptadas van de las humanísticas redonda ${ }^{49}$ y bastarda ${ }^{50}$ de los primeros tiempos a la pseudorredonda, según nomenclatura de Santiago Palomares $^{51}$. A veces se optará por modelos muy caligráficos recargados de trazos superfluos $^{52}$ o por el empleo de una escritura publicitaria, según la han definido Vicente García Lobo y Encarnación Martín ${ }^{53}$, en las primeras líneas ${ }^{54}$, destacándose sobre manera el nombre del novicio ya en religión ${ }^{55}$.

En cuanto a los motivos decorativos, estos son mucho menos vistosos que en sus homólogos femeninos ${ }^{56}$. En el mejor de los casos se llegó a emplear una suerte de decoración vegetal o algún motivo geométrico ${ }^{57}$. En este último sentido, algunas cédulas fueron enmarcadas en una viñeta ${ }^{58}$.

49 Cédula n. ${ }^{\circ} 16$.

50 Cédulas núms. 1, 2, 3, 4, 10, 13, 28...

51 Cédula n. ${ }^{\circ} 53$, por ejemplo. Sobre la difusión de este tipo de escritura en el siglo XVIII se han manifestado: Carmen del CAMINO MARTÍNEZ, Escritura y oficina en el siglo XVIII: la administración de correos de Lima, en Historia. Instituciones. Documentos, 36 (2009), pp. 86-90 y 93-101; más recientemente, Antonio J. LÓPEZ GUTIÉRREZ, La escritura en Hispanoamérica durante los siglos XVI-XVIII (nuevos horizontes de investigación), en VV.AA. (coords.), Paleografía y escritura hispánica, Madrid, 2016, p. 293.

52 Cédula n. ${ }^{\circ} 15$.

53 Vicente García Lobo, La escritura publicitaria, en M. ${ }^{a}$ Encarnación MaRTín LÓPEZ y Vicente GARCÍA LOBO (coords.), La inscripciones góticas. II Coloquio Internacional de Epigrafía Medieval, León, 2010, pp. 29-44; María Encarnación MARTín LÓPEZ, La escritura publicitaria, en Codex Biblicus Legionensis. Veinte estudios, León, 1999, p. 127; Francisco Reyes MARSILLA DE PASCUAL, La escritura publicitaria en el Libro Becerro del convento de Trinitarios de Murcia y sus calígrafos-iluminadores. Siglo XVII, en Ramón BALDAQUí ESCANDELL (ed.), Lugares de escritura: el monasterio, Alicante, 2016, p. 418.

54 Puede verse, por ejemplo, la cédula de fray Juan Martínez (n. ${ }^{\circ}$ 17), donde el nombre del profeso, en latín, se fijó en posición central en el tercio superior del bifolio, empleándose en ello una escritura mayúscula de distintos módulos. Vid. también cédulas núms. 14, 18, 22 o 23 . En la pieza . $^{\circ} 22$ del catálogo adjunto, para el nombre del postulante se emplea una mayúscula en caracteres de mayor módulo, no dejando de valerse de algún recurso específico; así, en el EGO FRATER FERDINANDUS, la $\mathrm{S}$ fue fijada entre los trazos verticales de la $\mathrm{U}$, mientras que para la I se aprovechó el primer trazo de la $\mathrm{D}$ que la precedía. También en escritura publicitaria el EGO F. MICHAEL de la cédula n. $^{\circ} 25$.

55 Lo mismo sucede en las femeninas. Vid. los numerosos ejemplos que ofrece Alicia MARCHANT RIVERA, Leyendas latinas en las cartas de profesión del Císter malagueño (1605-1805): la exégesis biblica al servicio del ceremonial religioso femenino, en Documenta \& Instrumenta, 15 (2017), pp. 69-89; Alicia MarCHANT Rivera, Aproximación a la diplomática eclesiástica... [ver n. 47], p. 324.

56 Alicia MARCHANT RIVERA, Aproximación a la diplomática eclesiástica... [ver n. 47], p. 321; María del Val GONZÁlEZ DE LA PEÑA, Aspectos gráficos... [ver n. 34], pp. 69-71.

57 El trazo vertical de la «E» inicial de la cédula de fray Andrés Félix Pacheco tiene forma de tronco de árbol, mientras que en los brazos superior e inferior simulan ramas con hojas. Catálogo, n. ${ }^{\circ} 9$.

$58 \mathrm{Vid}$., por ejemplo: cédula . $^{\circ} 18$; texto enmarcado por una triple línea perimetral (n. $\left.{ }^{\circ} 25\right)$, siendo la central más gruesa y roja (n. $\left.{ }^{\circ} 23\right)$ o sencillamente más gruesa en tinta parduzca (n. $\left.{ }^{\circ} 22\right)$; o con 
Por el contrario, la segunda parte de la cédula, que debemos al postulante, suele estar escrita en una cursiva currens, que muestra la mayor o menor pericia de este y un alejamiento absoluto de los modelos propuestos por los calígrafos ${ }^{59}$.

En otras ocasiones, las menos, ambos asientos parecen deberse a la mano del postulante, como puede verse en la cédula de fray Manuel Labrador ${ }^{60}$.

Como ha sido avanzado más arriba el papel empleado para escribir las cédulas de profesión no fue siempre el mismo. Un somero repaso al elenco de filigranas documentadas permite observar la procedencia de aquel. Con carácter general, puede afirmarse que entre los siglos XVI y XVII el monasterio se aprovisionó mayoritariamente de papel foráneo, muy posiblemente francés y genovés. En este último punto no se diferencia de lo que parece documentarse en otros monasterios de la congregación ${ }^{61}$.

La filigrana de la mano ${ }^{62}$ se constituye en la mayoritaria en los ejemplares más antiguos de la serie ${ }^{63}$, estando aquella rematada ya en una flor ${ }^{64}$, en una estre$11 a^{65}$ o en una cruz $^{66}$. Le sucede en el tiempo la marca de agua de la cruz inscrita en una circunferencia coronada ${ }^{67}$, motivo relativamente habitual a lo largo del seiscientos ${ }^{68}$.

Sin embargo, uno de los motivos más representado en la presente colección es la marca de agua de los tres círculos ${ }^{69}$. A ella ha dedicado José Carlos Balmace-

la cruz cortando las líneas horizontales superiores de dicho marco (n. $\left.{ }^{\circ} 26\right)$. Un modelo mucho más sencillo, con el texto que habría de leer el novicio en la ceremonia enmarcado por un par de líneas laterales puede verse en la cédula de Simeón Sánchez (n. $\left.{ }^{\circ} 10\right)$.

59 No obstante, en ocasiones, el recién ingresado emplea escrituras más fieles a los modelos de los calígrafos o, en su defecto, mucho más sentadas. Cédulas núms. 28, 43...

60 Cédula n. ${ }^{\circ} 44$.

61 Así, en Valdediós (Asturias), entre los gastos del último trimestre de 1662 se anotan «dos resmas de papel de Génova a veinte y ocho reales la resma». Con el tiempo, las partidas se seguirán sucediendo y en el último cuatrimestre de 1676 se vuelve a anotar la adquisición de papel genovés, gasto que se repetirá en el segundo balance del año 1678. Se hace necesario constar así mismo que entre las compras de papel, no faltan las anotaciones en las que no se deja constancia de su procedencia, tal y como sucede en las numerosas partidas incluidas en otros libros de caja. Ms. MADRID, AHN. Sección Clero. Regular. Cistercienses. Valdediós. L. 9399, sin foliar.

62 Oriol Valls i Subirà, La historia del papel en España, t. 2, Madrid, 1982, pp. 150-158.

63 Cédulas núms. 2, 3, 4, 5, 6, 7 y 10.

64 Cédulas núms. 5, 6, 7 y 10.

65 Cédulas núms. 2 y 4.

66 Cédula n. ${ }^{\circ} 3$.

67 Cédulas núms. 8, 11 y 13.

68 Oriol VAlls i SubiRÀ, La historia del papel... [ver n. 62], p. 61.

69 Cédulas núms. 12, 15, 17, 18, 19, 22, 23, 25, 26, 27, 28 y 30. Con media luna en el círculo superior, n. ${ }^{\circ} 29$. 
da un amplio estudio ${ }^{70}$ y no hay elenco de filigranas que no incorpore una amplia variedad de sus tipos ${ }^{71}$. Los tres círculos o medias lunas pueden ir coronados ${ }^{72}$ o rematados con una $\mathrm{cruz}^{73}$; en ocasiones la $\mathrm{cruz}^{74} \mathrm{u}$ otro motivo (un corazón, una o varias letras...) se sitúan en la base de aquellos. En cuanto a los signos que se insertan en los círculos, nos encontramos con cruces, corazones, letras... Los monjes de Valbuena adquieren estos papeles desde mediados del siglo XVII hasta el primer tercio del setecientos. El escudo de armas de Génova, con los dos leones a ambos flancos de una cruz inscrita en un círculo ${ }^{75}$ y coronada, acredita la procedencia italiana de esta tipología que tuvo difusión por toda Europa ${ }^{76}$.

Ya avanzado el siglo XVIII, cada vez con mayor frecuencia, este fue substituido por una producción local, si bien siguieron llegando materiales de otros centros de producción, ahora con total seguridad peninsulares ${ }^{77}$. Así, una de las cédulas, la de fray Joaquín Rojas de $1807^{78}$, fue escrita sobre un bifolio salido del ingenio que Francisco Reig llevaba en arriendo en Alcoy ${ }^{79}$ y cuyo papel fue distribuido por buena parte del territorio peninsular ${ }^{80}$, llegando algunas reme-

70 José Carlos BALMACEDA, La filigrana de los tres círculos en la documentación malagueña del siglo XVIII, en VV.AA., Actas del III Congreso Nacional de Historia del papel en España, Cuenca, 1999, pp. 273-293.

71 Taurino BURÓn CASTRO, Frecuencia de algunas clases de filigranas en el siglo XVII, en VV.AA., Actas del IX Congreso Nacional de Historial del Papel en España, Zaragoza, 2011, pp. 266-274; Paloma MARTÍneZ POVEDA, Aproximación al estudio del papel en el siglo XVIII alicantino. Filigranas en los libros de cabildos del archivo municipal de Alicante, en VV.AA., Actas del VI Congreso Nacional de Historial del Papel en España, Valencia, 2005, pp. 257-258; María Paloma CRUZ PASCUAL, Adquisición de material escriturario del cabildo catedralicio murciano en el siglo XVIII, en VV.AA., Actas del IV Congreso Nacional de Historia del Papel en España, Cuenca, 2001, pp. 152-153 y 160.

72 Cédulas núms. 19, 23, 30.

73 Cédulas núms. 15, 17, 22, 25, 26, 27, 29.

74 Cédulas núms. 19, 23 y 28.

75 Cédula n. ${ }^{\circ} 19$.

76 José Carlos BALmaCEDA, La filigrana de los tres círculos... [ver n. 70], p. 274. Judith Helvia GARCía MARTÍN, Música religiosa en la Castilla rural de los siglos XVIII y XIX. La capilla de música de la iglesia de los santos fuanes de Nava del Rey (1700-1890), Salamanca, 2011, p. 505; Alicia MARCHANT RIVERA, Aproximación a la diplomática eclesiástica... [ver n. 47], pp. 321-322.

77 A esta conclusión ha llegado también Judith Helvia GarCÍA MARTín, Música religiosa en la Castilla rural... [ver n. 76], p. 511.

78 Cédula n. ${ }^{\circ}$ 77. Jarrón con tres ramas de cardos, con el nombre de Francisco Reig en la base.

79 Ramón Molina Ferrero, Las chimeneas de ladrillo en la circunscripción industrial de Alcoi, en Recerques del Museu d'Alcoi, 20 (2011), p. 245. El molí dels Arquets había sido establecido en El Barxell por José Gonsálvez. Ha subrayado la importancia de Alcoy como centro papelero en el siglo XVIII, Oriol VALLS I SUBIRÀ, La historia del papel... [ver n. 62], p. 257. Además, entre otros, Miquel GUTIÉRREZ I POCH, Desarrollo de la manufactura papelera española durante el siglo XVIII, en VV.AA., Actas del IV Congreso Nacional de Historia del Papel en España, Cuenca, 2001, pp. 339-341.

80 Papel fabricado por Francisco Reig se documenta en Córdoba en 1806; Juan CASTELLÓ MORA, Papeles foráneos en la provincia de Córdoba. Archivos y bibliotecas destinados a la fabricación de papel, en VV.AA., Actas del IV Congreso Nacional de Historia del Papel en España, Cuenca, 2001, p. 381. 
sas con la misma filigrana a la ciudad de Oviedo, donde se estaba empleando en $1810^{81}$.

No obstante, para esos primeros años del siglo XIX los monjes de Valbuena continuaban nutriéndose, como hacían desde mediados del setecientos, del papel producido en molinos emplazados en la propia provincia de Valladolid. En 1749 se documenta la primera presencia de un papel en cuya filigrana se aprecian las letras IHS, rematadas en una cruz, inscritas en un sol; la última cédula escrita sobre este tipo de papel va fechada en febrero de $1753^{82}$. En su variante más compleja figura la fecha bajo el sol (año 1751), quedando este bajo el amparo de una corona ${ }^{83}$. Desconocemos la procedencia exacta de este papel, pero quizá saliese ya del molino que la Compañía de Jesús venía gestionando desde 1738 en Quintanilla de Abajo ${ }^{84}$. De hecho, desde 1754 hasta su expulsión ${ }^{85}$, los bernardos de Valbuena debieron de adquirir a los jesuitas buenas remesas de papel de buena calidad. La filigrana reproduce la palabra Compañía $\left(\mathrm{COMP}^{4}\right)^{86}$, acompañada frecuentemente por el año ${ }^{87} \mathrm{y}$, en ocasiones, con una corona sobrepuesta ${ }^{88}$.

Entre 1775 y 1804 la mayoría de cédulas fueron escritas sobre papeles salidos del mismo molino, del que los monjes vallisoletanos fueron adquiriendo sucesivas remesas ${ }^{89}$. En todas ellas podemos leer la palabra MALLO, cuyos tipos y disposición van modificándose con el tiempo: $\mathrm{O}$ final, que puede tomar la forma de herradura, abierta en el ojo por la parte inferior; mejora en el alineamiento de las letras... Además, dicha palabra puede ir acompañada de otros elementos. Así, va inscrita en el centro de un rombo rematado en el

81 María Dolores Díaz de Miranda y Ana María Herrero Montero, El papel en los libros de acuerdos del ayuntamiento de Oviedo. Años 1789 a 1812, en VV.AA., Actas del VI Congreso Nacional de Historia del Papel en España, Valencia, 2005, pp. 317 y 373.

82 Cédulas núms. 34, 35, 36, 37, 38, 39 y 40.

83 Cédulas núms. 37 y 38.

84 Gonzalo GaYOSO CARREIRA, Historia papelera de la provincia de Valladolid, en Investigación y Técnica del Papel, 17 (1968), pp. 645-646. El mismo pasaje reproducido en Gonzalo GAYOSO CARREIRA, Historia del papel en España, t. 1, Lugo, 1994, pp. 130-131 (filigrana en t. 3, p. 57). En cambio, Judith García en su documentado estudio señala que se trata de una casa desconocida (fechas extremas de 1752-1769), Judith Helvia GARCÍA MARTÍN, Música religiosa en la Castilla rural... [ver n. 76], p. 529.

85 La última cédula de profesión fue escrita en 1771 y es el único ejemplar en el que no figura año de producción. Cédula n. ${ }^{\circ} 53$.

86 Cédulas núms. 41 a 50 y 53.

871754 (cédula n. ${ }^{\circ} 41$ ), 1755 (n. ${ }^{\circ} 42$ ), 1756 (n. ${ }^{\circ} 43$ ), 1757 (n. ${ }^{\circ} 44$ ), 1759 (núms. 45 y 46), 1761 (n. $\left.{ }^{\circ} 47\right), 1763$ (núms. 48, 49 y 50).

88 Cédula n. ${ }^{\circ} 41$.

89 Cédulas núms. 57, 58, 59, 60, 61, 62, 63, 65, 67, 68, 70, 71, 72 y 74. 
vértice superior en una $\mathrm{cruz}^{90}$; aparecer en el tercio central o en el superior de una figura polilobulada que remata ya en una $\mathrm{cruz}^{91}$, o ya en una corona ${ }^{92}$. Del mismo modo, puede aparecer acompañando a una flor de lis ${ }^{93}$, o al pie de un castillo inserto en una circunferencia adornada con trazos curvilíneos ${ }^{94}$. Muy posiblemente se trate de un papel de origen vallisoletano ${ }^{95}$, ampliamente utilizado en la región ${ }^{96}$ y cuya comercialización llegó a inicios del siglo XIX a alcanzar la cornisa cantábrica ${ }^{97}$.

Con el retorno de los monjes al monasterio en 1823, tras su breve exclaustración durante el Trienio Liberal, la adquisición de papel local para escriturar las cédulas de profesión continuó siendo la tónica dominante. Los nueve ejemplares extendidos entre 1826 y 1833 se hicieron sobre papeles procedentes de un molino de Sardón de Duero, edificado en 1814 y propiedad de Millán Alonso del Barrio ${ }^{98}$. La marca de agua combina las palabras ALONSO y SARDÓN ${ }^{99}$, apareciendo cada una de ellas, de forma habitual, a mitad de pliego.

90 Cédula n. ${ }^{\circ}$ 58. Reproducida en Judith Helvia GarCÍA MARTÍN, Música religiosa en la Castilla rural... [ver n. 76], n. 193 .

91 Cédula n. ${ }^{\circ} 68$.

92 Cédulas núms. 63 y 65.

93 Cédulas núms. 61, 62 y con un motivo más sencillo n. ${ }^{\circ}$ 74. En la cédula 61 puede verse bajo la palabra MALLO una A, muy posiblemente correspondiente a Alonso.

94 Cédula 71. Reproducida en Judith Helvia GarCía MaRTín, Música religiosa en la Castilla rural... [ver n. 76], p. 517 (figura 204).

95 Proponen la procedencia vallisoletana María Dolores DíAZ DE MiRANDA MaCÍAS y Ana María Herrero MONTERo, El papel en los libros de acuerdos del ayuntamiento de Oviedo. Años 1789... [ver n. 81], pp. 315 y 328. García Martín señala el probable origen castellano de este papel, frente a Valls i Subirà que lo creía originario de Valencia. Judith Helvia GARCía MARTín, Música religiosa en la Castilla rural... [ver n. 76], pp. 515-516.

96 Así lo ha constatado para el último cuarto del siglo XVIII y los primeros años del XIX, Judith Helvia GARCÍA MARTíN, Música religiosa en la Castilla rural... [ver n. 76], pássim.

97 En Oviedo, sendas filigranas con la palabra MALLO se documentan en los años 1800, 1807 y 1812; María Dolores DíaZ DE Miranda MaCías y Ana María Herrero MonTERo, El papel en los libros de acuerdos del ayuntamiento de Oviedo. Años 1789... [ver n. 81], pp. 315 y 367 (núms. 65 y 66); María Dolores Díaz de Miranda MAcías y Ana María Herrero MonTero, El papel en los libros de acuerdos del ayuntamiento de Oviedo. Años 1811-1830, en VV.AA., Actas del VII Congreso Nacional de Historia del Papel en España, Madrid, 2007, pp. [15 y 59]

98 Gonzalo GAYOSO CARREIRA, Historia papelera... [ver n. 84], p. 640; el mismo pasaje reproducido en Gonzalo GaYOSO CARREIRA, Historia del papel... [ver n. 84], pp. 131-132. Judith Helvia GARCÍA MARTíN, Música religiosa en la Castilla rural... [ver n. 76], pp. 513-514. También María Dolores Díaz de Miranda MaCÍAS y Ana María Herrero MonTERo, Filigranas en el Libro de Reales Órdenes (1816-1825) del archivo municipal de Oviedo, en VV.AA., Actas del VI Congreso Nacional de Historia del Papel en España, Cuenca, 2001, pp. 239-240 y 256.

99 Cédulas núms. 81, 82, 83, 84, 85, 86, 87, 88 y 89. 
Otras filigranas con motivos heráldicos, blasones, con coronas, uno o dos círculos... se hallan escasamente representadas en esta colección y no resulta fácil determinar su procedencia.

\section{APROXIMACIÓN A LA SOCIOLOGÍA MONÁSTICA}

Como ha sido ya señalado, el número de cédulas de profesión aquí analizadas y que se ofrecen en el catálogo adjunto, no se corresponde con el número total de hijos de la abadía. Por tanto, el estudio de la vecindad de las familias de los profesos desde un punto de vista cuantitativo no resulta concluyente, del mismo modo que tampoco podemos valorar una posible evolución diacrónica en su justa medida.

En la muestra, dentro del reino de Galicia, la actual provincia de Orense resulta un importante lugar de origen de las vocaciones ${ }^{100}$, por delante de Pontevedra, Lugo o La Coruña. Además, no pocos procedían de términos sitos hoy en las provincias de Madrid, Toledo o Ciudad Real. De tierra de Campos, un número significativo era oriundo de localidades y aldeas emplazadas dentro de los límites de Valladolid o Zamora. Naturales de Asturias, de las montañas de Burgos (actual Cantabria) o de La Rioja también tomaron hábito en Valbuena. Finalmente, se incorporaron naturales de diócesis y territorios ajenos a la influencia de la Congregación de Castilla como Tudela (Navarra), Andoain (Guipúzcoa) o Bordalba (Zaragoza).

En todo caso, las dos Castillas constituyen las dos principales zonas de procedencia, igual que sucede en Sobrado (La Coruña) entre los siglos XVI y XIX ${ }^{101}$, o en Valdediós (Asturias) entre 1778 y $1835^{102}$. En cambio, en Rioseco, en el siglo XVIII, según Bardeci, abundaba el número de monjes de origen gallego, al menos a juzgar por sus apellidos ${ }^{103}$.

100 En San Clodio, un buen número de monjes gallegos procedían de la diócesis de Tuy. Ms. LugO, ArChivo del monasterio de San Julián de Samos. Fondo San Clodio. Libro de tomas de hábito y profesiones.

101 Es cierto que con importantes oscilaciones en el tiempo. Ofelia REY CASTELAO, El clero regular de la diócesis compostelana en la Edad Moderna, en José GARCÍA ORO (dir.), Historia de las diócesis españolas. 14. Iglesias de Santiago de Compostela y Tuy-Vigo, Madrid, 2002, p. 366. María SEIJAS MonTERO, Análisis sociológico y actividad cultural de los claustros cistercienses en la Galicia Moderna, en Estudios Humanisticos, 9 (2010), p. 36.

102 Baudilio Barreiro Mallón, La presencia de los bernardos en Asturias en la Edad Moderna, en VV.AA., Actas [del] Congreso Internacional sobre San Bernardo e o Císter en Galicia e Portugal, Orense, 1992, pp. 768-769.

${ }^{103}$ Inocencio CADIÑANOS BARDECI, El monasterio cisterciense de Santa María de Rioseco. Historia y cartulario, Villarcayo, 2004, p. 30. 
Muchos de los que tomaron el hábito en Valbuena procedían de pequeños núcleos o parroquias rurales de Galicia (Brantuas, parroquia de San Julián de Brantuas; San Clodio; San Martín da Cova...), Asturias (Puelles, San Félix de Hevia, Rozadas), Cantabria (Sobarzo) o Castilla (Ribadelago, en Zamora). El mundo urbano no está mal representado, tanto con núcleos de entidad y prestigio (Sevilla, Bilbao, Astorga, Huete, Cuéllar...) como con villas de tamaño medio, más o menos importantes (Alcázar de San Juan, Campo de Criptana, Quintanar de la Orden, Ocaña, Manzanares, Curiel, Herce...).

En cuanto a la edad de profesión de los que pedían hábito para monje de coro, esta parece que fue reduciéndose con el paso del tiempo, tal y como también se ha apreciado para Sobrado ${ }^{104}$. Los escasos datos para los siglos XVI y XVII apenas permiten intuir que aquella fue ligeramente superior a la que se registra para la segunda mitad del siglo XVIII y para el primer tercio del siglo XIX, periodo para el que la serie muestra una mayor continuidad. Entre 1740 y 1835, la edad media se sitúa por encima de los 17 años y por debajo de los 18, salvo en la primera década del siglo XIX, cuando se supera esta última cifra $(18,8)$.

La edad mínima documentada en las cédulas recogidas en el catálogo es la de los 16 años que contemplaban las definiciones de la orden desde $1683^{105}$, siendo un porcentaje significativo el de los que profesan con más de 20 años, especialmente en los primeros siglos. De hecho, de los 22 novicios que profesan como coristas entre 1594 y 1699, nueve lo hacen con los 20 años cumplidos (cerca del $41 \%)$. Entre 1700 y 1833 apenas suponen un $15 \%$. Por norma general, los que profesaban como legos eran individuos de mayor edad.

\section{CONCLUSIONES}

Estas 89 cédulas no constituyen sino una mínima parte de las que debieron de custodiarse en el archivo del monasterio de Valbuena de Duero, pues fue una de las más importantes casas matrices de la Congregación cisterciense de Castilla, especialmente en los siglos XV, XVI y XVII. Perdió peso específico a medida que otras casas fueron ascendiendo a la categoría de matrices.

En todo caso, la muestra nos ha permitido conocer con detalle la elaboración del tipo documental (estructura diplomática, modelos gráficos, soporte...) en el que

104 María Seijas Montero, Análisis sociológico... [ver n. 100], p. 34.

105 Sobre esta cuestión en las constituciones de la Congregación, Guillermo FERNÁNDEZ ORTIZ, Escrituras para la profesión [ver n. 27], pp. 211 y ss. 
quienes abandonaban el siglo para ingresar en el monasterio expresaban su compromiso de vinculación con la Orden. Se ha constatado que la calidad material y el proceso de elaboración no alcanzan los niveles de sus homólogas femeninas.

En último lugar, hemos podido ofrecer unas notas sobre la profesión en el monasterio vallisoletano, atendiendo a las edades a las que se efectuaban las profesiones, así como a la procedencia geográfica de los postulantes, que puede verse más ampliamente en el catálogo que figura a continuación.

\section{Catálogo}

\section{$-1-$}

1594, abril, 11.- Valbuena de Duero.

Cédula de profesión de fray Ambrosio Pérez, natural de Santa María de Nieva, bijo de Juan Pérez y de Ana Cortés, en el monasterio de Valbuena de Duero, siendo abad fray [Juan] Bautista de Villalba.

A.- AHN. Sección Clero. Regular. Cistercienses. Valbuena de Duero. 7658.

Papel. 316 × $220 \mathrm{~mm}$.

1599, septiembre, 26.- Valbuena de Duero.

Cédula de profesión de fray Lorenzo de la Torre, natural de la villa de Manzanares (Ciudad Real), bijo de Martín de la Torre y de Sebastiana García, en el monasterio de Valbuena de Duero, siendo abad fray Francisco Portes.

A.- AHN. Sección Clero. Regular. Cistercienses. Valbuena de Duero. 7658.

Papel. Sin medidas. Mal estado de conservación, la tinta ha consumido parte del papel.

$-3-$

1603, noviembre, 11.- Valbuena de Duero.

Cédula de profesión de fray Antonio Sánchez, natural de Cervatos (Cantabria), bijo de Francisco Sánchez Caballero y de Ana del Campo, en el monasterio de Valbuena de Duero, siendo abad fray Malaquías de Vega.

A.- AHN. Sección Clero. Regular. Cistercienses. Valbuena de Duero. 7658.

Papel. 420 x $297 \mathrm{~mm}$.

1604, abril, 18.- Valbuena de Duero.

\section{$-4-$}

Cédula de profesión de fray Diego de Paz, bijo de Lucas de Paz y de doña Leonor del Río, en el monasterio de Valbuena de Duero, siendo abad fray Malaquías de Vega.

A.- AHN. Sección Clero. Regular. Cistercienses. Valbuena de Duero. 7658.

Papel. 423 x $296 \mathrm{~mm}$. 
1606, abril, 25.- Valbuena de Duero.

Cédula de profesión de fray Prudencio López, de la villa de Soto, bijo de Diego López y de María Marín, en el monasterio de Valbuena de Duero, siendo abad fray Julián Ordónez.

A.- AHN. Sección Clero. Regular. Cistercienses. Valbuena de Duero. 7658.

Papel. 417 × $288 \mathrm{~mm}$.

$-6-$

1611, abril, 7.- Valbuena de Duero.

Cédula de profesión de fray Jerónimo de Fuentelcarnero, de Ocaña (Toledo), bijo de Fuan Alonso de Fuentelcarnero, en el monasterio de Valbuena de Duero, siendo abad fray gaspar de Úbeda.

A.- AHN. Sección Clero. Regular. Cistercienses. Valbuena de Duero. 7658.

Papel. $300 \times 420 \mathrm{~mm}$.

$$
-7-
$$

1613, marzo, 21.- Valbuena de Duero.

Cédula de profesión de fray Benito del Castillo, de la ciudad de Tudela (Navarra), bijo de José del Castillo y de María Tafalla, en el monasterio de Valbuena de Duero, siendo abad fray [fuan] Bautista de Villalba.

A.- AHN. Sección Clero. Regular. Cistercienses. Valbuena de Duero. 7658.

Papel. $421 \times 302 \mathrm{~mm}$.

$-8-$

1616, febrero, 2.- Valbuena de Duero.

Cédula de profesión de fray Francisco de Céspedes, de Salinas de Rosío (Burgos), bijo de Juan de Céspedes y de doña María de la Peña, en el monasterio de Valbuena de Duero, siendo abad fray Bernardo Lasarte.

A.- AHN. Sección Clero. Regular. Cistercienses. Valbuena de Duero. 7658.

Papel. 307 x $415 \mathrm{~mm}$.

$-9-$

1623, agosto, 15.- Valbuena de Duero.

Cédula de profesión fray Andrés Félix Pacheco en el monasterio de Valbuena de Duero, siendo abad fray Andrés Prieto.

A.- AHN. Sección Clero Regular. Cistercienses. Valbuena de Duero. Legajo 7658 (1).

Papel. $438 \times 282 \mathrm{~mm}$.

$-10-$

1627, febrero, 2.- Valbuena de Duero.

Cédula de profesión de fray Simeón Sánchez, de Valdemoro (Madrid), diócesis de Toledo, hijo de Alonso Sánchez y de Ana Santos, en el monasterio de Valbuena de Duero, siendo abad fray Benito Pérez.

A.- AHN. Sección Clero. Regular. Cistercienses. Valbuena de Duero. 7658.

Papel. $295 \times 211 \mathrm{~mm}$. 


\section{GUILLERMO FERNÁNDEZ ORTIZ}

$-11-$

1638, enero, 21.- Valbuena de Duero.

Cédula de profesión de fray Mauro de Cano, de El Toboso (Toledo), bijo de Pedro Alonso y de Ana Sánchez Cano, en el monasterio de Valbuena de Duero.

A.- AHN. Sección Clero. Regular. Cistercienses. Valbuena de Duero. 7658.

Papel. $430 \times 314 \mathrm{~mm}$.

$-12-$

1640, agosto, 8.- Valbuena de Duero.

Cédula de profesión de fray Miguel de Robles, de la villa de Cea (León), hijo de Miguel Alonso y de Beatriz de Robles, en el monasterio de Valbuena de Duero, siendo abad fray Pablo de Quirós.

A.- AHN. Sección Clero. Regular. Cistercienses. Valbuena de Duero. 7658.

Papel. 423 x $311 \mathrm{~mm}$. Manchas de humedad.

$-13-$

1647, marzo, 10.- Valbuena de Duero.

Cédula de profesión de fray Miguel Alcalde, de Ausejo (La Rioja), bijo de Juan Alcalde, en el monasterio de Valbuena de Duero, siendo abad fray Pedro Berganza.

A.- AHN. Sección Clero. Regular. Cistercienses. Valbuena de Duero. 7658.

Papel. 317 x $426 \mathrm{~mm}$. Mal estado de conservación, con rotura que afecta al texto.

$-14-$

1653, octubre, 18.- Valbuena de Duero.

Cédula de profesión de fray Benito González, de Buendía (Cuenca), bijo de Miguel González y de Ana de Arribas, en el monasterio de Valbuena, siendo abad fray Lucas Fajardo.

A.- AHN. Sección Clero. Regular. Cistercienses. Valbuena de Duero. 7658.

Papel. 430 × $310 \mathrm{~mm}$. Rota en el pliegue central.

$-15-$

1655, febrero, 2.- Valbuena de Duero.

Cédula de profesión de fray Eugenio Sánchez Calderón, de la villa de Vega (Valladolid), bijo de Pedro Sánchez Calderón, en el monasterio de Valbuena de Duero, siendo abad fray Bernardo Suárez.

A.- AHN. Sección Clero. Regular. Cistercienses. Valbuena de Duero. 7658.

Papel. 424 x $302 \mathrm{~mm}$.

$-16-$

1660, agosto, 29.- Valbuena de Duero.

Cédula de profesión de fray Bartolomé de Ortega, bijo de Domingo de Ortega y de Catalina Parra, en el monasterio de Valbuena de Duero, siendo abad fray Simeón Sánchez.

A.- AHN. Sección Clero. Regular. Cistercienses. Valbuena de Duero. 7658.

Papel. $315 \times 436 \mathrm{~mm}$. 


\section{CÉDULAS DE PROFESIÓN DEL MONASTERIO DE VALBUENA DE DUERO...}

1672, noviembre, 1.- Valbuena de Duero.

Cédula de profesión de fray Juan Martínez de San Pedro, de Sobarzo, en las Montañas de Burgos (Cantabria), hijo de Juan Martínez de San Pedro y de María de la Prada, en el monasterio de Valbuena de Duero, siendo abad fray Simeón Sánchez.

A.- AHN. Sección Clero. Regular. Cistercienses. Valbuena de Duero. 7658.

Papel. 418 × 297 mm. Regular estado, viéndose afectada su lectura.

$-18-$

1673, enero, 22.- Valbuena de Duero.

Cédula de profesión de fray Francisco Fernández de Hervás, de Ocaña (Toledo), bijo de Luis Fernández de Hervás y de María de Marfil, en el monasterio de Valbuena de Duero, siendo abad fray Tomás de Argüello.

A.- AHN. Sección Clero. Regular. Cistercienses. Valbuena de Duero. 7658.

Papel. $310 \times 427 \mathrm{~mm}$.

1687, septiembre, 8.- Valbuena de Duero.

Cédula de profesión para lego de fray Bernardo Lorenzo de Aguiar, de San Martín da Cova (Lugo), bijo de Gregorio Lorenzo de Aguiar y de Inés López, en el monasterio de Valbuena de Duero, siendo abad fray Alonso de Nieva.

A.- AHN. Sección Clero. Regular. Cistercienses. Valbuena de Duero. 7658.

Papel. 309 x $430 \mathrm{~mm}$.

$$
-20-
$$

1690, diciembre, 6.- Valbuena de Duero.

Cédula de profesión como hermano lego de fray fosé fordán, de la villa de Simancas (Valladolid), bijo de Pedro Fordán y de Antonia de Paz, en el monasterio de Valbuena, siendo abad fray Alonso de Valcárcel.

A.- AHN. Sección Clero. Regular. Cistercienses. Valbuena de Duero. 7658.

Papel. 308 x $429 \mathrm{~mm}$.

$$
-21-
$$

1694, febrero, 21.- Valbuena de Duero.

Cédula de profesión de fray Cristóbal de Prado, de Puertollano, en Campo de Calatrava (Ciudad Real), hijo de don Cristóbal de Prado y de doña Clara Rosales, en el monasterio de Valbuena de Duero, siendo abad fray Baltasar García.

A.- AHN. Sección Clero. Regular. Cistercienses. Valbuena de Duero.7658.

Papel. 416 × $297 \mathrm{~mm}$. 


\section{GUILLERMO FERNÁNDEZ ORTIZ}

1696, mayo, 3.- Valbuena de Duero.

Cédula de profesión de fray Fernando de Castro, de la villa de Olivares (de Duero), bijo de don Francisco de Castro y de Eufrasia Padillo, en el monasterio de Valbuena de Duero, siendo abad fray Simeón Sanz.

A.- AHN. Sección Clero. Regular. Cistercienses. Valbuena de Duero. 7658.

Papel. 417 x $298 \mathrm{~mm}$.

$$
-23-
$$

1696, octubre, 28.- Valbuena de Duero.

Cédula de profesión de fray Alonso de la Puente, del lugar de Ribadelago, aldea de la Puebla de Sanabria (Zamora), hijo de Domingo de la Puente y de Antonia Castaña, en el monasterio de Valbuena de Duero, siendo abad fray Simeón Sanz.

A.- AHN. Sección Clero. Regular. Cistercienses. Valbuena de Duero. 7658.

Papel. 424 x $301 \mathrm{~mm}$.

\section{$-24-$}

1697, marzo, 29.- Valbuena de Duero.

Cédula de profesión como bermano lego de fray Diego Toledo, de Pezuela de las Torres, cerca de Alcalá (Madrid), hijo de ferónimo Toledo y de Ana Montero, en el monasterio de Valbuena de Duero, siendo abad fray Simeón Sanz.

A.- AHN. Sección Clero. Regular. Cistercienses. Valbuena de Duero. 7658.

Papel. $427 \times 310 \mathrm{~mm}$.

1699, noviembre, 1.- Valbuena de Duero.

Cédula de profesión de fray Miguel de la Calle, de la ciudad de Huete (Cuenca), bijo de Bartolomé de la Calle y de Polonia de Tarancón, en el monasterio de Valbuena de Duero, siendo abad fray Alonso de Valcárcel.

A.- AHN. Sección Clero. Regular. Cistercienses. Valbuena de Duero. 7658.

Papel. 433 x $306 \mathrm{~mm}$.

1700, junio, 29.- Valbuena de Duero.

$-26-$

Cédula de profesión como hermano lego de fray Pablo Castrillo, de Ampudia, en Campos (Palencia), bijo Francisco Castrillo y de Ana Fernández, en el monasterio de Valbuena de Duero, siendo abad fray Alonso de Valcárcel.

A.- AHN. Sección Clero. Regular. Cistercienses. Valbuena de Duero. 7658.

Papel. 424 x $309 \mathrm{~mm}$.

1706, mayo, 2.- Valbuena de Duero.

Cédula de profesión de fray Miguel García en el monasterio de Valbuena, de la quintería de Santa María de Pozos, obispado de Cuenca, bijo de Manuel García y de Catalina García Delgado, en el monasterio de Valbuena, siendo abad fray Alonso Valcárcel.

A.- AHN. Sección Clero. Regular. Cistercienses. Valbuena de Duero. 7658.

Papel. 404 x 306 mm. 


\section{CÉDULAS DE PROFESIÓN DEL MONASTERIO DE VALBUENA DE DUERO...}

$-28-$

1725, septiembre, 16.- Valbuena de Duero.

Cédula de profesión de fray Agustín López, del lugar de Villaralbo (Zamora), bijo de Francisco López y de María Esteva, en el monasterio de Valbuena de Duero, siendo abad fray Alfonso Ferrer.

A.- AHN. Sección Clero. Regular. Cistercienses. Valbuena de Duero. 7658.

Papel. 297 x $415 \mathrm{~mm}$. Señales de humedad, con el texto desvahído en la parte superior. Roturas.

\section{$-29-$}

1725, noviembre, 11.- Valbuena de Duero.

Cédula de profesión de fray Simón Varela, del lugar de Brantuas, parroquia de San Julián de Brantuas (La Coruña), en el monasterio de Valbuena de Duero, siendo abad fray Alfonso Ferrer.

A.- AHN. Sección Clero. Regular. Cistercienses. Valbuena de Duero. 7658.

Papel. 300 x $425 \mathrm{~mm}$. Tiene manchas de moho.

1726, agosto, 28.- Valbuena de Duero.

Cédula de profesión como hermano lego de fray Andrés Pérez, de Bordalba (Zaragoza), bijo de Bartolomé Pérez u de María Marco, en el monasterio de Valbuena de Duero, siendo abad fray Alfonso Ferrer.

A.- AHN. Sección Clero. Regular. Cistercienses. Valbuena de Duero. 7658.

Papel. 304 x 426 mm. Tiene manchas de moho.

1730, mayo, 1.- Valbuena de Duero.

Cédula de profesión de fray Roberto Ruano, de Villada (Palencia), bijo de Bonifacio Ruano y de Juana González, en el monasterio de Valbuena, siendo abad fray Manuel Montiel.

A.- AHN. Sección Clero. Regular. Cistercienses. Valbuena de Duero. 7658.

Papel. 301 x $404 \mathrm{~mm}$. Pequeña rotura en el pliegue central; el texto no se ve afectado.

1731, noviembre, 25.- Valbuena de Duero.

Cédula de profesión de fray Malaquías de Ubillos, de la villa de Andoain (Guipúzcoa), bijo de fuan de Ubillos y de María de Lizárraga, en el monasterio de Valbuena de Duero, siendo abad fray Cristóbal de Prado.

A.- AHN. Sección Clero. Regular. Cistercienses. Valbuena de Duero. 7658.

Papel. $302 \times 419 \mathrm{~mm}$.

1739, junio, 16.- Valbuena de Duero.

Cédula de profesión de fray Vicente Ferrer, de la villa de Villada (Palencia), bijo don Bernardo Ferrer y de doña Catalina Conejo, en el monasterio de Valbuena de Duero, siendo abad fray Joaquín.

A.- AHN. Sección Clero. Regular. Cistercienses. Valbuena de Duero. 7658.

Papel. 303 x $410 \mathrm{~mm}$. 


\section{GUILLERMO FERNÁNDEZ ORTIZ}

1749, septiembre, 14.- Valbuena de Duero.

Cédula de profesión de fray Antonio Ruiz, de la villa de Santillana (Cantabria), bijo de don fuan Antonio Ruiz de Somavía y de doña Josefa García, en el monasterio de Valbuena de Duero, siendo abad fray Luis Muñoz.

A.- AHN. Sección Clero. Regular. Cistercienses. Valbuena de Duero. 7658.

Papel. $428 \times 307 \mathrm{~mm}$.

$$
-35-
$$

1749, septiembre, 14.- Valbuena de Duero.

Cédula de profesión de fray Hipólito Quirós, de Campo de Criptana (Ciudad Real), bijo de don Martín Quirós y de doña María Núñez, en el monasterio de Valbuena de Duero, siendo abad fray Luis Muñoz.

A.- AHN. Sección Clero. Regular. Cistercienses. Valbuena de Duero. 7658.

Papel. 427 × $298 \mathrm{~mm}$.

$-36-$

1750, abril, 4.- Valbuena de Duero.

Cédula de profesión de fray Benito García, del lugar de Penouta (Orense), bijo de don Pedro García y de doña Ana González, siendo abad fray Luis Muñoz.

A.- AHN. Sección Clero. Regular. Cistercienses. Valbuena de Duero. 7658.

Papel. $421 \times 305 \mathrm{~mm}$.

$$
-37-
$$

1751, diciembre, 8.- Valbuena de Duero.

Cédula de profesión de fray Andrés Pardo, de Piedrafita, bijo de don Agustín Pardo y de doña Antonia María Arias, en el monasterio de Valbuena de Duero, siendo abad fray Andrés de la Carrera.

A.- AHN. Sección Clero. Regular. Cistercienses. Valbuena de Duero. 7658.

Papel. 425 x $305 \mathrm{~mm}$.

$$
-38-
$$

1751, diciembre, 8.- Valbuena de Duero.

Cédula de profesión de fray Mauro Pérez ${ }^{106}$, de la villa de la Mota del Cuervo, hijo de Diego Pérez y Naharro y de María de Bustos, en el monasterio de Valbuena de Duero, siendo abad fray Andrés de la Carrera.

A.- AHN. Sección Clero. Regular. Cistercienses. Valbuena de Duero. 7658.

Papel. $427 \times 305 \mathrm{~mm}$.

106 En la documentación de la orden aparecerá con mayor frecuencia como fray Mauro Naharro. Así figura como testigo en las cédulas núms. 45 y 46, y también en el libro de difuntos del padre Blanco, cuando fallece entre 1799 y 1801. Ms. PonTEVEdRA, MUSEO DE PONTEVEDRA. Fondo Casto Sampedro. 32-4, p. 50. 


\section{CÉDULAS DE PROFESIÓN DEL MONASTERIO DE VALBUENA DE DUERO...}

$-39-$

1751, diciembre, 21.- Valbuena de Duero.

Cédula de profesión de fray Plácido Martínez, de la villa de Autol (La Rioja), hijo de José Martínez y de María Frías en el monasterio de Valbuena de Duero, siendo abad fray Andrés de la Carrera.

A.- AHN. Sección Clero. Regular. Cistercienses. Valbuena de Duero. 7658.

Papel. 417 x $303 \mathrm{~mm}$.

1753, febrero, 4.- Valbuena de Duero.

$-40-$

Cédula de profesión de fray Anselmo Salgado, de la parroquia de San Clodio (Lugo), bijo de don Facinto Salgado y Araujo y de doña Manuela Gómez, en el monasterio de Valbuena de Duero, siendo abad fray Andrés de la Carrera.

A.- AHN. Sección Clero. Regular. Cistercienses. Valbuena de Duero. 7658.

Papel. $429 \times 306 \mathrm{~mm}$.

$$
-41-
$$

1754, diciembre, 3.- Valbuena de Duero.

Cédula de profesión de fray Gregorio Galdámez, de la ciudad de Alfaro (La Rioja), bijo de Bartolomé Gáldamez y de Andrea Arévalo, en el monasterio de Valbuena, siendo abad fray Gregorio Muñoz.

A.- AHN. Sección Clero. Regular. Cistercienses. Valbuena de Duero. 7658.

Papel. 414 × $294 \mathrm{~mm}$.

$-42-$

1755, diciembre, 8.- Valbuena de Duero.

Cédula de profesión de fray Eugenio Moreno, de Villarías (Burgos), bijo de fuan Moreno y de fuana Villagarcía, en el monasterio de Valbuena de Duero, siendo abad fray Gregorio Muñoz.

A.- AHN. Sección Clero. Regular. Cistercienses. Valbuena de Duero. 7658.

Papel. 411 x $297 \mathrm{~mm}$.

$$
-43-
$$

1757, junio, 24.- Valbuena de Duero.

Cédula de profesión de fray Malaquias Lisasoain, hijo de don Marcos Lisasoain, natural de la provincia de Navarra, y de doña María Luna, natural de Sevilla, en el monasterio de Valbuena de Duero, siendo abad fray Adriano Palmero.

A.- AHN. Sección Clero. Regular. Cistercienses. Valbuena de Duero. 7658.

Papel. 424 x $309 \mathrm{~mm}$.

\section{$-44-$}

1758, mayo, 19.- Valbuena de Duero.

Cédula de profesión de fray Manuel Labrador, de la villa de Fermoselle (Zamora), bijo de Fuan Labrador y de Teresa González, en el monasterio de Valbuena de Duero, siendo abad fray Adriano Palmero.

A.- AHN. Sección Clero. Regular. Cistercienses. Valbuena de Duero. 7658.

Papel. $421 \times 305 \mathrm{~mm}$. 


\section{GUILLERMO FERNÁNDEZ ORTIZ}

$-45-$

1760, noviembre, 18.- Valbuena de Duero.

Cédula de profesión de fray Ángel Salmón, del lugar de Camargo (Cantabria), bijo de Pascual Salmón y de María Fernández, en el monasterio de Valbuena, siendo abad fray Ángel Muñoz.

A.- AHN. Sección Clero. Regular. Cistercienses. Valbuena de Duero. 7658.

Papel. $308 \times 425 \mathrm{~mm}$.

$$
-46-
$$

1760, noviembre, 18.- Valbuena de Duero.

Cédula de profesión de fray Fernando Mateo, de la villa de Campo Real (Madrid), bijo de Pedro Mateo y de María de Lara, en el monasterio de Valbuena de Duero, siendo abad fray Ángel Muñoz.

A.- AHN. Sección Clero. Regular. Cistercienses. Valbuena de Duero. 7658.

Papel. 309 x $422 \mathrm{~mm}$.

$-47-$

1762, junio, 10.- Valbuena de Duero.

Cédula de profesión de fray Bernardo Funco, de la ciudad de Astorga, bijo de don Fosé Funco y de doña Josefa Pimentel, en el monasterio de Valbuena, siendo abad fray Angel Muñoz.

A.- AHN. Sección Clero. Regular. Cistercienses. Valbuena de Duero. 7658.

Papel. 298 x $416 \mathrm{~mm}$.

$-48-$

1764, octubre, 14.- Valbuena de Duero.

Cédula de fray Fulgencio Santos, de Barzamedelle (Leiro, Orense), hijo de don Miguel Santos y de doña Francisca de Puga, en el monasterio de Valbuena de Duero, siendo abad fray Fulgencio.

A.- AHN. Sección Clero. Regular. Cistercienses. Valbuena de Duero. 7658.

Papel. 309 x $430 \mathrm{~mm}$.

1764, diciembre, 8.- Valbuena de Duero.

Cédula de profesión de fray Prudencio Palacio, de San Félix de Hevia, concejo de Siero (Asturias), bijo de Domingo Antonio Palacio y de Luisa Argüelles, en el monasterio de Valbuena de Duero, siendo abad fray Fulgencio.

A.- AHN. Sección Clero. Regular. Cistercienses. Valbuena de Duero. 7658.

Papel. 308 x $421 \mathrm{~mm}$.

$-50-$

1766, noviembre, 30.- Valbuena de Duero.

Cédula de profesión de fray Edmundo (Miguel) Mondragón ${ }^{107}$, de Socuéllamos, en La Mancha, partido del priorato de Santiago (Ciudad Real), bijo de Juan Mondragón y de Fosefa Moreno, en el monasterio de Valbuena, siendo abad fray Andrés Pardo.

A.- AHN. Sección Clero. Regular. Cistercienses. Valbuena de Duero. 7658.

Papel. 304 x $425 \mathrm{~mm}$.

107 Aunque en el cuerpo del texto es denominado Edmundo, suscribe como fray Miguel. En el libro de difuntos de fray Gregorio Blanco también figura como fray Miguel Mondragón. PONTEVEDRA, MUSEO DE Pontevedra. Fondo Casto Sampedro. 34-04, p. 60. 


\section{CÉDULAS DE PROFESIÓN DEL MONASTERIO DE VALBUENA DE DUERO...}

$-51-$

1768, diciembre, 8.- Valbuena de Duero.

Cédula de profesión ¿para lego? de fray Santiago del Valle, del lugar de Lamela (Orense), hijo de don Juan Cayetano del Valle y de doña Bernarda Sorribas, en el monasterio de Valbuena de Duero, siendo abad fray Plácido Martínez.

A.- AHN. Sección Clero. Regular. Cistercienses. Valbuena de Duero. 7658.

Papel. 293 x $407 \mathrm{~mm}$.

$$
-52-
$$

1769, octubre, 1.- Valbuena de Duero.

Cédula de profesión de fray Alonso Villar, de Pozoantiguo (Zamora), bijo de ferónimo Villar y de Ana Rollón, en el monasterio de Valbuena de Duero, siendo abad fray Plácido Martínez.

A.- AHN. Sección Clero. Regular. Cistercienses. Valbuena de Duero. 7658.

Papel. $285 \times 407 \mathrm{~mm}$.

$$
-53-
$$

1771, febrero, 24.- Valbuena de Duero.

Cédula de profesión de fray Plácido Sáez, bijo de Manuel Sáez y de María Arévalo, en el monasterio de Valbuena de Duero, siendo abad fray Plácido Martínez.

A.- AHN. Sección Clero. Regular. Cistercienses. Valbuena de Duero. 7658.

Papel. $308 \times 426 \mathrm{~mm}$.

$$
-54-
$$

1772, octubre, 21.- Valbuena de Duero.

Cédula de profesión de fray Adriano Alonso, de Vezdemarbán (Zamora), bijo de Santos Alonso y de Francisca, en el monasterio de Valbuena de Duero, siendo abad fray Adriano Palmero.

A.- AHN. Sección Clero. Regular. Cistercienses. Valbuena de Duero. 7658.

Papel. 296 x $417 \mathrm{~mm}$.

$$
-55-
$$

1772, octubre, 21.- Valbuena de Duero.

Cédula de profesión de fray Lucas Carralbal, de San Clodio, bijo de don Fosé Carralbal y de doña Francisca Araújo, en el monasterio de Valbuena, siendo abad fray Adriano Palmero.

A.- AHN. Sección Clero. Regular. Cistercienses. Valbuena de Duero. 7658.

Papel. 304 x $420 \mathrm{~mm}$.

$$
-56-
$$

1773, agosto, 16.- Valbuena de Duero.

Cédula de profesión de fray Alberico Vázquez, de Villanubla (Valladolid), bijo de don Francisco Vázquez y de doña Isabel Lobo, en el monasterio de Valbuena de Duero, siendo abad fray Adriano Palmero.

A.- AHN. Sección Clero. Regular. Cistercienses. Valbuena de Duero. 7658.

Papel. 284 x $398 \mathrm{~mm}$. 


\section{GUILLERMO FERNÁNDEZ ORTIZ}

$-57-$

1775, mayo, 1.- Valbuena de Duero.

Cédula de profesión de fray Roberto Fernández, de Refojos [reino de Galicia], bijo de Antonio Fernández y de Fosefa Fernández, en el monasterio de Valbuena, siendo abad fray Adriano Palmero.

A.- AHN. Sección Clero. Regular. Cistercienses. Valbuena de Duero. 7658.

Papel. $310 \times 417 \mathrm{~mm}$.

$-58-$

1778, junio, 14.- Valbuena de Duero.

Cédula de profesión de fray Andrés Sánchez, de Pola de Siero (Asturias), hijo de Toribio Sánchez y de Rosa Rodríguez Campal, en el monasterio de Valbuena de Duero, siendo abad fray Cristóbal Pozo.

A.- AHN. Sección Clero. Regular. Cistercienses. Valbuena de Duero. 7658.

Papel. $293 \times 373 \mathrm{~mm}$.

$-59-$

1778, octubre, 4.- Valbuena de Duero.

Cédula de profesión de fray Fosé Millán, de Alcázar de San Fuan (Ciudad Real), hijo de fosé Millán y de Elena Ligero, en el monasterio de Valbuena de Duero, siendo abad fray Zuan Cristóbal Pozo.

A.- AHN. Sección Clero. Regular. Cistercienses. Valbuena de Duero. 7658.

Papel. 304 x $419 \mathrm{~mm}$.

$-60-$

1779, septiembre, 12.- Valbuena de Duero.

Cédula de profesión de fray Gabriel Álvarez, del lugar de Sorga (Orense), bijo de Manuel Álvarez y de Gestrudis Araújo, en el monasterio de Valbuena de Duero, siendo abad fray Raimundo Fusto.

A.- AHN. Sección Clero. Regular. Cistercienses. Valbuena de Duero. 7658.

Papel. 305 x $414 \mathrm{~mm}$.

$-61-$

1782, diciembre, 6.- Valbuena de Duero.

Cédula de profesión de fray Nicolás Álvarez, de Madridejos (Toledo), bijo de Antonio Álvarez y de Vicenta García, en el monasterio de Valbuena de Duero, siendo abad fray Nicolás Aldao.

A.- AHN. Sección Clero. Regular. Cistercienses. Valbuena de Duero. 7658.

Papel. 312 x $430 \mathrm{~mm}$.

$-62-$

1783, mayo, 1.- Valbuena de Duero.

Cédula de profesión [¿para lego?] de fray Damián de Cáceres, del lugar de Cobos, bijo de Pedro de Cáceres y de Mariana de Castro, siendo abad fray Nicolás Aldao.

A.- AHN. Sección Clero. Regular. Cistercienses. Valbuena de Duero. 7658.

Papel. 310 x 410 mm. 


\section{CÉDULAS DE PROFESIÓN DEL MONASTERIO DE VALBUENA DE DUERO...}

$-63-$

1785, febrero, 20.- Valbuena de Duero.

Cédula de profesión de fray Malaquías Pérez, del lugar de Abezames (Zamora), hijo de Diego Pérez y de Ana Dominguez, en el monasterio de Valbuena de Duero, siendo abad fray Malaquías Lisasoain.

A.- AHN. Sección Clero. Regular. Cistercienses. Valbuena de Duero. 7658.

Papel. $310 \times 430 \mathrm{~mm}$.

$-64-$

1785, octubre, 28.- Valbuena de Duero.

Cédula de fray Frastrado Fernández en el monasterio de Valbuena, de la villa de Miguel Esteban (Toledo), bijo de Fosé Fernández y de Rafaela García, en el monasterio de Valbuena de Duero, siendo abad fray Malaquías Lisasoaín.

A.- AHN. Sección Clero. Regular. Cistercienses. Valbuena de Duero. 7658.

Papel. $308 \times 426 \mathrm{~mm}$.

$-65-$

1785, octubre, 28.-Valbuena de Duero.

Cédula de profesión de fray Alfredo o Alredo de Ibargüen, de Bilbao, hijo de José Agustín de Ibargüen y de María Felipa de Achutegi, en el monasterio de Valbuena de Duero, siendo abad fray Malaquías Lisasoaín.

A.- AHN. Sección Clero. Regular. Cistercienses. Valbuena de Duero. 7658.

Papel. $310 \times 426 \mathrm{~mm}$.

$-66-$

1787, junio, 29.- Valbuena de Duero.

Cédula de profesión de fray Pablo Crisóstomo Arias, de Allariz (Orense), bijo de don Alonso [Arias] y de doña Agustina Rodríguez, en el monasterio de Valbuena de Duero, siendo abad fray Bernardo Junco.

A.- AHN. Sección Clero. Regular. Cistercienses. Valbuena de Duero. 7658.

Papel. 305 x $425 \mathrm{~mm}$.

$$
-67-
$$

1789, julio, 25.- Valbuena de Duero.

Cédula de profesión de fray Benito Rodríguez, de Berrueces (Valladolid), bijo de Antonio [Rodríguez] y de Catalina Fernández, en el monasterio de Valbuena de Duero, siendo abad fray Bernardo Funco.

A.- AHN. Sección Clero. Regular. Cistercienses. Valbuena de Duero. 7658.

Papel. $310 \times 424 \mathrm{~mm}$.

$-68-$

1791, febrero, 2.- Valbuena de Duero.

Cédula de profesión de fray Salvador Rodríguez, de San Mamed, obispado de Astorga, reino de Galicia (Orense), hijo de Francisco Rodríguez y de doña Isabel Cales, en el monasterio de Valbuena de Duero, siendo abad fray Bernardo funco.

A- AHN. Sección Clero. Regular. Cistercienses. Valbuena de Duero. 7658.

Papel. 309 x $419 \mathrm{~mm}$. 


\section{GUILLERMO FERNÁNDEZ ORTIZ}

$-69-$

1793, mayo, 25.- Valbuena de Duero.

Cédula de profesión de fray Hipólito Hernández, de Cuelgamures Zamora), bijo de Juan Hernández y de María Hernández, en el monasterio de Valbuena de Duero, siendo abad fray Hipólito Quirós.

A.- AHN. Sección Clero. Regular. Cistercienses. Valbuena de Duero. 7658.

Papel. $303 \times 422 \mathrm{~mm}$.

$-70-$

1793, octubre, 6.- Valbuena de Duero.

Cédula de profesión de fray Isidoro Nuño, bijo de Francisco Nuño y de María Alonso, en el monasterio de Valbuena de Duero, siendo abad fray Hipólito Quirós.

A.- AHN. Sección Clero. Regular. Cistercienses. Valbuena de Duero. 7658.

Papel. 308 x $422 \mathrm{~mm}$.

$-71-$

1795, septiembre, 29.- Valbuena de Duero.

Cédula de profesión de fray Luis España, de la villa de Santa María de Ribarredonda (Burgos), bijo de Luis de España y de Victora Foncea, en el monasterio de Valbuena de Duero, siendo abad fray Fulgencio Santos.

A.- AHN. Sección Clero. Regular. Cistercienses. Valbuena de Duero. 7658.

Papel. 307 x $428 \mathrm{~mm}$.

$-72-$

1798, julio, 25.- Valbuena de Duero.

Cédula de profesión de fray Fulgencio Feijóo, del lugar de Beade (Pontevedra), bijo de don Pedro Feijoo $y$ de doña Rita Collaza, en el monasterio de Valbuena de Duero, siendo abad fray Fulgencio Santos.

A.- AHN. Sección Clero. Regular. Cistercienses. Valbuena de Duero. 7658.

Papel. 306 x $417 \mathrm{~mm}$.

$-73-$

1803, julio, 10.- Valbuena de Duero.

Cédula de profesión de fray Carlos Galilea, del lugar de Herce (La Rioja), bijo de don Fuan Galilea y Aragón y de doña Francisca Eguía y Quirós, en el monasterio de Valbuena de Duero, siendo abad fray Joaquín [Magdaleno].

A.- AHN. Sección Clero. Regular. Cistercienses. Valbuena de Duero. 7658.

Papel. 303 x $418 \mathrm{~mm}$.

1804, marzo, 11.- Valbuena de Duero.

Cédula de profesión de fray Gregorio Palomino, de Colmenar de Oreja (Madrid), bijo de Eugenio Palomino y de Segunda Martínez, en el monasterio de Valbuena de Duero, siendo abad fray Foaquín [Magdaleno].

A.- AHN. Sección Clero. Regular. Cistercienses. Valbuena de Duero. 7658.

Papel. $311 \times 426 \mathrm{~mm}$. 


\section{CÉDULAS DE PROFESIÓN DEL MONASTERIO DE VALBUENA DE DUERO...}

1806, julio, 9.- Valbuena de Duero.

Cédula de profesión de fray Clemente Cuevas, de Rioseco de las Cinco Villas (Cantabria), bijo de Francisco Cuevas y de Ángela Macho, en el monasterio de Valbuena de Duero, siendo abad fray Joaquín [Magdaleno].

A.- AHN. Sección Clero. Regular. Cistercienses. Valbuena de Duero. 7658.

Papel. 297 x $426 \mathrm{~mm}$.

$$
-76-
$$

1806, septiembre, 22.- Valbuena de Duero.

Cédula de profesión de[l bermano lego] fray Bernardo Martín ${ }^{108}$, de Valbuena de Duero (Valladolid), hijo de Marcos Martín y de María Calvo, en el monasterio de Valbuena de Duero, siendo abad fray Joaquín [Magdaleno].

A.- AHN. Sección Clero. Regular. Cistercienses. Valbuena de Duero. 7658.

Papel. 307 x $423 \mathrm{~mm}$. Roturas en el cuarto inferior del pliego; no afectan al texto.

$$
-77-
$$

1807, marzo, 21.- Valbuena de Duero.

Cédula de profesión de fray Joaquín Rojas, de la villa de Curiel (Valladolid), hijo de Luis Rojas y de Teresa Rebolledo, en el monasterio de Valbuena de Duero, siendo abad fray foaquín [Magdaleno].

A.- AHN. Sección Clero. Regular. Cistercienses. Valbuena de Duero. 7658.

Papel. 275 × $390 \mathrm{~mm}$.

$-78-$

1807, marzo, 21.- Valbuena de Duero.

Cédula de profesión de fray Eugenio Maestre, de la villa de Cuéllar (Segovia), hijo de Manuel Maestre y de Manuela Sanz, en el monasterio de Valbuena de Duero, siendo abad fray Joaquín [Magdaleno].

A.- AHN. Sección Clero. Regular. Cistercienses. Valbuena de Duero. 7658.

Papel. $283 \times 394 \mathrm{~mm}$.

1807, junio, 24.- Valbuena de Duero.

Cédula de profesión de fray Francisco Favier Criado, de Villalón [de Campos] (Valladolid), hijo de Pedro Criado y María Herrero, en el monasterio de Valbuena de Duero, siendo abad fray Vicente [Arquero].

A.- AHN. Sección Clero. Regular. Cistercienses. Valbuena de Duero. 7658.

Papel. $302 \times 424 \mathrm{~mm}$.

108 La cédula nada dice de que sea lego, pero así consta en las informaciones de moribus et vita, en las que se indica exactamente que fue admitido para oficio de hortelano. Ms. MADRID, AHN. Sección Clero. Regular. Cistercienses. Valbuena de Duero. 7658. 


\section{GUILLERMO FERNÁNDEZ ORTIZ}

$-80-$

1807, julio, 12.- Valbuena de Duero.

Cédula de profesión fray Pedro Alonso, hijo de Francisco Alonso y de Pa<s>cua Núñez, vecinos del lugar de Friames de [San Verísimo de] Pontedeva (Orense), en el monasterio de Valbuena de Duero, siendo abad fray Vicente [Arquero].

A.- AHN. Sección Clero Regular. Cistercienses. Valbuena de Duero. Legajo 7658 (2).

Papel. 304 x $424 \mathrm{~mm}$.

$$
-81-
$$

1826, abril, 23.- Valbuena de Duero.

Cédula de profesión de fray Manuel Carrera, de la parroquia de San Bartolomé de Puelles, jurisdicción de Valdediós (Vilaviciosa, Asturias), bijo de Blas Carrera y de Juana García Poladura, siendo abad fray Roberto [Campo].

A.- AHN. Sección Clero. Regular. Cistercienses. Valbuena de Duero. 7658.

Papel. 314 x $439 \mathrm{~mm}$. Mínimas roturas en los pligues.

$-82-$

1826, agosto, 20.- Valbuena de Duero.

Cédula de profesión de fray Luis Monsalve, de la villa de Pareja (Guadalajara), bijo de Antonio Monsalve Santero y de María Ángela Monsalve Asenjo, en el monasterio de Valbuena, siendo abad fray Roberto [Campo].

A.- AHN. Sección Clero. Regular. Cistercienses. Valbuena de Duero. 7658.

Papel. 297 x $423 \mathrm{~mm}$.

$$
-83-
$$

1827, marzo, 11.- Valbuena de Duero.

Cédula de profesión de fray Roberto Martín Tejedor, del lugar de Tiedra (Valladolid), bijo de Evaristo Martín y de Isabel Tejedor, en el monasterio de Valbuena de Duero, siendo abad fray Roberto [Campo].

A.- AHN. Sección Clero. Regular. Cistercienses. Valbuena de Duero. 7658.

Papel. 312 x $436 \mathrm{~mm}$.

$-84-$

1828, julio, 2.- Valbuena de Duero.

Cédula de profesión de fray Diego Díaz Marta, de la villa de Quintanar de la Orden (Toledo), bijo de Domingo Díaz Marta y de Antonia Tirado, en el monasterio de Valbuena de Duero, siendo abad fray Froilán Hernández.

A.- AHN. Sección Clero. Regular. Cistercienses. Valbuena de Duero. 7658.

Papel. 308 x $433 \mathrm{~mm}$. 
1830, junio, 6.- Valbuena de Duero.

Cédula de profesión de fray Francisco Sánchez, de la villa de Hervás (Cáceres), bijo de Manuel Sánchez y de Teresa Hernández, en el monasterio de Valbuena de Duero, siendo abad fray Froilán Hernández.

A.- AHN. Sección Clero. Regular. Cistercienses. Valbuena de Duero. 7658.

Papel. 220 × $315 \mathrm{~mm}$.

$-86-$

1830, junio, 6.- Valbuena de Duero.

Cédula de profesión de fray Froilán Oliveros, de la villa de Lillo (Toledo), hijo de Manuel Oliveros y de María Cano, en el monasterio de Valbuena, siendo abad fray Froilán Hernández.

A.- AHN. Sección Clero. Regular. Cistercienses. Valbuena de Duero. 7658.

Papel. $217 \times 315 \mathrm{~mm}$.

$-87-$

1833, abril, 21.- Valbuena de Duero.

Cédula de profesión de fray Felipe Sopeña, de Rozadas (Villaviciosa, Asturias), bijo de Ignacio Sopeña y de María Sánchez, en el monasterio de Valbuena de Duero, siendo abad fray Atanasio Rivas.

A.- AHN. Sección Clero. Regular. Cistercienses. Valbuena de Duero. 7658.

Papel. $311 \times 432 \mathrm{~mm}$.

$-88-$

1833, abril, 21.- Valbuena de Duero.

Cédula de profesión de fray Zosé García, de San Miguel de Osmo (Orense), hijo de Francisco García $y$ de Josefa González, en el monasterio de Valbuena de Duero, siendo abad fray Atanasio Rivas.

A.- AHN. Sección Clero. Regular. Cistercienses. Valbuena de Duero. 7658.

Papel. 314 x $431 \mathrm{~mm}$.

$-89-$

1833, abril, 21.- Valbuena de Duero.

Cédula de profesión de fray Vicente Novoa, de La Barouta (San Clodio, Orense), bijo de Manuel Novoa y de Agustina Giráldez, en el monasterio de Valbuena de Duero, siendo abad fray Atanasio Rivas.

A.- AHN. Sección Clero. Regular. Cistercienses. Valbuena de Duero. 7658.

Papel. 312 x $434 \mathrm{~mm}$. Roturas en los pliegues. 


\section{GUILLERMO FERNÁNDEZ ORTIZ}

\section{REFERENCIAS BIBLIOGRÁFICAS}

Álvarez Palenzuela, Vicente y Recuero Astray, Manuel, La fundación de monasterios cistercienses en Castilla: cuestiones cronológicas e ideológicas, en Hispania Sacra, 74 (1984), pp. 429455.

BALMACEDA, José Carlos, La filigrana de los tres círculos en la documentación malagueña del siglo XVIII, en VV.AA., Actas del III Congreso Nacional de Historia del papel en España, Cuenca, 1999, pp. 273-293.

BarReiro Mallón, Baudilio, La presencia de los bernardos en Asturias en la Edad Moderna, en VV.AA., Actas [del] Congreso Internacional sobre San Bernardo e o Císter en Galicia e Portugal, Orense, 1992, pp. 759-772.

BURÓN CASTRO, Taurino, Frecuencia de algunas clases de filigranas en el siglo XVII, en VV.AA., Actas del IX Congreso Nacional de Historial del Papel en España, Zaragoza, 2011, pp. 266-274.

CADIÑANOS BARDECI, Inocencio, El monasterio cisterciense de Santa María de Rioseco. Historia $y$ cartulario, Villarcayo, 2004.

CALleja PUeRTA, Miguel, Libros para la administración. Estado de la cuestión y perspectivas de la investigación, en José Antonio MUNITA LOINAZ y José Ángel LEMA PUEYO (coords.), La escritura de la memoria. Libros para la administración, Bilbao, 2012, pp. 17-39.

CAMINO MARTíNEZ, Carmen del, Escritura y oficina en el siglo XVIII: la administración de correos de Lima», en Historia. Instituciones. Documentos, 36 (2009), pp. 73-110.

CANSECo Oyarbide, Ana María, El monasterio cisterciense de Santa María la Real de Arévalo: cédulas de profesión, Oviedo (Tesis de Licenciatura inédita), 1994.

CASTElló Mora, Juan, Papeles foráneos en la provincia de Córdoba. Archivos y bibliotecas destinados a la fabricación de papel, en VV.AA., Actas del IV Congreso Nacional de Historia del Papel en España, Cuenca, 2001, pp. 377-396.

Cavero Domínguez, Gregoria, Catálogo del monasterio de San Miguel de Dueñas, León, 1994.

Cruz Herranz, Luis Miguel de la, La sección de Clero del Archivo Histórico Nacional, en Juan Carlos GALENDE (coord.), II Fornadas científicas sobre documentación de la Corona de Castilla (siglos XIII-XV), Madrid, 2003, pp. 373-432.

Cruz Pascual, María Paloma, Adquisición de material escriturario del cabildo catedralicio murciano en el siglo XVIII, en VV.AA., Actas del IV Congreso Nacional de Historia del Papel en España, Cuenca, 2001, pp. 149-162.

Díaz de Miranda MaCías, María Dolores y Herrero MonTero, Ana María, El papel en los libros de acuerdos del ayuntamiento de Oviedo. Años 1789 a 1812, en VV.AA., Actas del VI Congreso Nacional de Historia del Papel en España, Valencia, 2005, pp. 303-384.

- El papel en los libros de acuerdos del ayuntamiento de Oviedo. Años 1811-1830, en VV.AA., Actas del VII Congreso Nacional de Historia del Papel en España, Madrid, 2007, pp. 205-282.

— Filigranas en el Libro de Reales Órdenes (1816-1825) del archivo municipal de Oviedo, en VV.AA., Actas del VI Congreso Nacional de Historia del Papel en España, Cuenca, 2001, pp. 237-274.

FERNÁNDEZ ORTIZ, Guillermo, Escrituras para la profesión masculina en la orden del Císter, ceremonial y tipologías documentales, en Historia. Instituciones. Documentos, 44 (2017), pp. 103-130.

GARCÍA FLORES, Antonio, Arquitectura de la Orden del Císter en la Provincia de Valladolid (11471515), Valladolid, 2010. 


\section{CÉDULAS DE PROFESIÓN DEL MONASTERIO DE VALBUENA DE DUERO...}

- Monje, contrabandista, abad y promotor de las cartas: el patrocinio de fray Alonso de la Puente ( 1729) en el monasterio de Valbuena (Valladolid), en Boletín de la Real Academia de Bellas Artes de la Purísima Concepción, 44 (2009), pp. 61-74.

GARCÍA LOBO, Vicente, La escritura publicitaria, en Encarnación MARTÍN LÓPEZ y Vicente GARCÍA LOBO (coords.), La inscripciones góticas. II Coloquio Internacional de Epigrafía Medieval, León, 2010, pp. 29-44.

GARCÍA MARTÍN, Judith Helvia, Música religiosa en la Castilla rural de los siglos XVIII y XIX. La capilla de música de la iglesia de los santos Juanes de Nava del Rey (1700-1890), Salamanca, 2011.

GaYOso CarreIRA, Gonzalo, Historia del papel en España, Lugo, 1994.

- Historia papelera de la provincia de Valladolid», en Investigación y Técnica del Papel, 17 (1968), pp. 931-946.

GONZÁleZ DE LA PEÑa, María del Val, Aspectos gráficos y visuales de las cartas de profesión monásticas, en Signo, 4 (1997), pp. 67-78.

GUTIÉRREZ I POCH, Miquel, Desarrollo de la manufactura papelera española durante el siglo XVIII, en VV.AA., Actas del IV Congreso Nacional de Historia del Papel en España, Cuenca, 2001, pp. 335-350.

La Regla de San Benito (edición de de García M. Colombás), Madrid, 1979.

Laso Ballesteros, Ángel, Eppur si muove: El Archivo Histórico Provincial de Valladolid, en Soledad CARNICER ARRIBAS y Alberto MARCOS MARTÍN (coords.), Valladolid, ciudad de archivos, Valladolid, 2011, pp. 213-255.

LÓPEZ GUTIÉRREZ, Antonio J., La escritura en Hispanoamérica durante los siglos XVI-XVIII (nuevos horizontes de investigación), en VV.AA (coords.), Paleografía y escritura hispánica, Madrid, 2016, pp. 268-294.

MARCHANT RIVERA, Alicia, Aproximación a la diplomática eclesiástica a través de la documentación conventual: las cartas de profesión de la abadía cisterciense de Santa Ana en Málaga, en Boletín de la Sociedad Española de Ciencias y Técnicas Historiográficas, 3 (2005), pp. 319-330.

- Las religiosas del císter malagueño. Catálogo de las cartas de profesión de la abadía de Santa Ana, Málaga, 2010.

- Leyendas latinas en las cartas de profesión del Císter malagueño (1605-1805): la exégesis bíblica al servicio del ceremonial religioso femenino, en Documenta \& Instrumenta, 15 (2017), pp. 69-89.

Marsilla de PASCUAL, Francisco Reyes, La escritura publicitaria en el Libro Becerro del convento de Trinitarios de Murcia y sus calígrafos-iluminadores. Siglo XVII, en Ramón BALDAQUí ESCANDELL (ed.), Lugares de escritura: el monasterio, Alicante, 2016, pp. 417-426.

MARTín LÓPeZ, María Encarnación, La escritura publicitaria, en Codex Biblicus Legionensis. Veinte estudios, León, 1999, pp. 127-142.

MartíneZ Poveda, Paloma, Aproximación al estudio del papel en el siglo XVIII alicantino. Filigranas en los libros de cabildos del archivo municipal de Alicante, en VV.AA., Actas del VI Congreso Nacional de Historial del Papel en España, Valencia, 2005, pp. 247-264.

MATÉ SADORNIL, Lorenzo, Cuentas del monasterio de Valbuena (s. XV), en VV.AA., VI Encuentro de trabajo sobre Historia de la Contabilidad [sin lugar], 2009, pp. [1-12].

MOLINA FERRERO, Ramón, Las chimeneas de ladrillo en la circunscripción industrial de Alcoi, en Recerques del Museu d'Alcoi, 20 (2011), pp. 217-292. 


\section{GUILLERMO FERNÁNDEZ ORTIZ}

PÉREZ-EMBID WAMBA, Javier, El Císter en Castilla y León. Monacato y dominios rurales (ss. XIIXV), Salamanca, 1986.

- Violencias y luchas campesinas en el marco de los dominios cistercienses castellanos y leoneses de la Edad Media, en VV.AA., El Pasado Histórico de Castilla y León. Volumen I: Edad Media, Burgos, 1983, pp. 161-178.

PONCET, Oliver, Inscrire les clercs dans l'État. La monarchie française, les ecclésiastiques et le gouvernement par l'écrit (XVI ${ }^{e}$-XVIII ${ }^{e}$ siècle), en Patrick ARABEYRE y Brigitte BASDEVANTGAUDEMENT (dirs.), Les clercs et les princes. Doctrines et pratiques de l'autorité ecclésiastique à l'époque moderne, Paris, 2013, pp. 79-103.

ReY CASTELaO, Ofelia, El clero regular de la diócesis compostelana en la Edad Moderna, en José García ORO (dir.), Historia de las diócesis españolas. 14. Iglesias de Santiago de Compostela y Tuy-Vigo, Madrid, 2002, pp. 352-408.

Seijas Montero, María, Análisis sociológico y actividad cultural de los claustros cistercienses en la Galicia Moderna, en Estudios Humanísticos, 9 (2010), pp. 25-49.

VALLS I SUBIRÀ, Oriol, La historia del papel en España, Madrid, 1982.

Zaragoza Pascual, Ernesto, Abadologio del monasterio de Nuestra Señora de la Anunciación del Bueso (1460-1789), en Investigaciones Históricas, 21 (2001), pp. 19-46.

\section{REFERENCIAS DE ARCHIVO}

Ms. Lugo, ARCHIVO Del MONASTERIO De SAn Julián De SAMOS. Fondo San Clodio. Libro de tomas de hábito y profesiones.

Ms. MADRID, AHN. Sección Clero. Regular. Cistercienses. Valbuena de Duero. Legajos 7658, 7660,7661 y 7666. 